\title{
Headache and immunological/autoimmune disorders: a comprehensive review of available epidemiological evidence with insights on potential underlying mechanisms
}

Leonardo Biscetti ${ }^{1}$, Gioacchino De Vanna², Elena Cresta², Ilenia Corbelli², Lorenzo Gaetani², Letizia Cupini ${ }^{3}$, Paolo Calabresi ${ }^{4}$ and Paola Sarchielli ${ }^{2^{*}}$

\begin{abstract}
Several lines of evidence support a role of the immune system in headache pathogenesis, with particular regard to migraine. Firstly, alterations in cytokine profile and in lymphocyte subsets have been reported in headache patients. Secondly, several genetic and environmental pathogenic factors seem to be frequently shared by headache and immunological/autoimmune diseases. Accordingly, immunological alterations in primary headaches, in particular in migraine, have been suggested to predispose some patients to the development of immunological and autoimmune diseases. On the other hand, pathogenic mechanisms underlying autoimmune disorders, in some cases, seem to favour the onset of headache. Therefore, an association between headache and immunological/ autoimmune disorders has been thoroughly investigated in the last years. The knowledge of this possible association may have relevant implications in the clinical practice when deciding diagnostic and therapeutic approaches. The present review summarizes findings to date regarding the plausible relationship between headache and immunological/autoimmune disorders, starting from a description of immunological alteration of primary headaches, and moving onward to the evidence supporting a potential link between headache and each specific autoimmune/immunological disease.
\end{abstract}

Keywords: Headache, Migraine, Autoimmune diseases, Immunological disorders, Neuroinflammation, Immune system, Cytokines

\footnotetext{
* Correspondence: paola.sarchielli@unipg.it

${ }^{2}$ Section of Neurology, Department of Medicine and Surgery, University of Perugia, Perugia, Italy

Full list of author information is available at the end of the article
}

(c) The Author(s). 2021 Open Access This article is licensed under a Creative Commons Attribution 4.0 International License, which permits use, sharing, adaptation, distribution and reproduction in any medium or format, as long as you give appropriate credit to the original author(s) and the source, provide a link to the Creative Commons licence, and indicate if changes were made. The images or other third party material in this article are included in the article's Creative Commons licence, unless indicated otherwise in a credit line to the material. If material is not included in the article's Creative Commons licence and your intended use is not permitted by statutory regulation or exceeds the permitted use, you will need to obtain permission directly from the copyright holder. To view a copy of this licence, visit http://creativecommons.org/licenses/by/4.0/ The Creative Commons Public Domain Dedication waiver (http://creativecommons.org/publicdomain/zero/1.0/) applies to the data made available in this article, unless otherwise stated in a credit line to the data. 


\section{Highlights}

- Immunological events may be involved in the pathophysiology of primary headaches

- In many autoimmune diseases headache prevalence is higher than in general population

- For many autoimmune diseases headache may be a risk factor or a clinical manifestation

\section{Introduction}

Headache is one of the most common neurological disorders and one of the most frequent reasons for medical consultation, both in primary care and in specialist settings.

Headaches are divided into primary-without an underlying cause-and secondary, those caused by other pathological conditions including trauma, haemorrhagic or ischemic lesions, tumours and infectious or inflammatory diseases. Clinicians need to consider all of the systemic and neurological signs, as well as laboratory findings, which are associated with headache, so to exclude a secondary form. The differential diagnosis between primary and secondary headaches is crucial, since it significantly influences clinical management, particularly from a therapeutic point of view.

Among secondary forms, headache has been suggested to be a neurological manifestation of many immunological/autoimmune disorders, both those primarily involving the central nervous system (CNS), such as multiple sclerosis, and those systemic, such as systemic lupus erythematosus. Based on this, over the last decades, researchers have focused their attention on better understanding possible links between headache and immunological/autoimmune diseases.

Both at epidemiological and pathophysiological levels, headache and immunological/autoimmune disorders seem to share common features. Most evidence in this field concerns migraine; thus, in this review, we will discuss mainly findings from studies specifically investigating a possible link between migraine and autoimmune diseases.

Epidemiologically, most immunological/autoimmune diseases are more frequent in females [1, 2]; likewise, almost all primary headache forms are more commonly diagnosed in females too, except for cluster headache [3]. Furthermore, the onset of both headache and immunological/autoimmune disorders are generally at young ages, with few exceptions, such as primary biliary cirrhosis and Graves' disease [4].

In terms of pathophysiology, in primary headaches, and mainly in the migraine context, the role of both neuroinflammation and immune system derangement has been increasingly acknowledged in the last decades, further supporting the view of a link of these conditions with immunological disorders. Nevertheless, the relevance of a common pathophysiological background of headache and immunological/autoimmune diseases is still a matter of debate. Specifically, it is not clear whether headache is a direct, specific manifestation of a disease or a comorbidity, whether it is reactive to disease or its direct organic consequence and, most importantly, if headache, and in particular migraine, can predispose persons to the subsequent development of an immunological/autoimmune disorder.

\section{Neuroinflammatory mechanisms involved in headache}

Nowadays, the relevance of the contribution of neuroinflammation in the pathophysiology of several painful conditions, including migraine, is widely accepted $[5,6]$. Neuroinflammation could also be involved in pathophysiological mechanisms of cluster headache but evidence in this regard are limited and dated, whereas its contribution to pathophysiological events underlying tension-type headache is unlikely. Neuroinflammatory mechanisms have also been described in the context of several disorders causing secondary headache, such as post-traumatic stress disorder, chronic stress and traumatic brain injury $[7,8]$.

Specifically, pre-clinical models of migraine demonstrated that, a key role in its pathophysiology is played by the trigemino-vascular system activation, which typically induces a local neurogenic inflammation involving dural and pial vessels. This causes (i) a plasma protein extravasation due to an increased meningeal vascular permeability, and (ii) the activation of immune cells, namely resident mast cells and perhaps macrophages, localized near the dural afferents. Activated mast cells in turn produce several mediators including serotonin, histamine, heparin, proteases and arachidonic acid products, pro-inflammatory cytokines and chemokines. All these substances are strongly involved in the peripheral sensitization of trigeminal endings [9]. Sensitized trigeminal c fibres release calcitonin gene-related peptide (CGRP) which interacts with its own receptors on the dural vessels. This interaction determines vessel dilation by activating adenylate cyclase which is responsible for the increase of intracellular cyclic adenosine monophosphate and the decrease in intracellular $\mathrm{Ca} 2+[10]$. In rodent models, CGRP also interacts with its own receptors on mast cells contributing to the release of inflammatory substances and cytokines, but this mechanism cannot be automatically translated to humans because of the lack of evidence of the presence of all components of CGRP receptors on human mast cells. Other neuropeptides such as pituitary adenylate cyclase-activating peptide or vasoactive intestinal peptide could play a role in mast cell activation and degranulation $[11,12]$. 
Peripheral sensitization of the primary afferent trigeminal ganglion (TG) neurons leads to the subsequent central sensitization of trigeminal nucleus caudalis (TNC) second-order neurons which in turn induces the sensitization of third-order neurons in the thalamus. The maintenance of sensitization of neurons in structures involved in the processing of trigemino-cervical nociception is believed to drive the progression from episodic to chronic migraine [13, 14].

In the TG, CGRP binds to A delta TG neurons expressing CGRP receptors facilitating nociceptive transmission to second-order neurons in the TNC. Resident glial cells and astrocytes also possess CGRP receptors. The interaction of CGRP with its receptors on these cells induces the release of some pro-inflammatory cytokines such as tumour necrosis factor (TNF)- $\alpha$ and Interleukin (IL)-1ß which dramatically amplifies trigeminal nociception $[15,16]$.

The upregulation of pro-inflammatory cytokines-specifically IL-1ß-in activated microglia has also been shown in the TNC. Using different models of trigeminal activation, the nuclear factor kappa-light-chain-enhancer of the activated B cell (NF-Kb) signalling pathway and activation of NLR family pyrin domain containing 3 (NLRP) inflammasome were found to play a role in neuron-glia cross-talk contributing to the central sensitization [17-20].

Neuroinflammatory events involving activated microglia and astrocytes also occur in the course of cortical spreading depression (CSD), which is considered the pathophysiological substrate of migraine with aura (MA). Several preclinical studies revealed that CSD not only induces glial activation but also increases the expression of pro-inflammatory cytokines, adhesion models and chemokines as well the expression of toll-like receptors (TLR3 and TLR4) [21-25]. A neuroimaging study on MA patients, using a radioligand binding the $18-\mathrm{kDa}$ translocator protein, a marker of glial activation, showed increased uptake in areas involved in nociceptive processing such as the thalamus primary/secondary somatosensory cortex and insular cortex as well as in areas primarily involved in CSD generation such as the visual cortex. This increased uptake appeared to be related to the frequency of attacks [26].

\section{The role of the derangement of the immune system in primary headaches suggested pathophysiological links with immunological/ autoimmune disorders}

Immunological and autoimmune disorders include several diseases or conditions caused by a dysfunction of the immune system.
Specifically, autoimmune diseases are characterized by abnormal immune responses to self-antigens resulting in a damage or dysfunction of a wide range of body tissues. Autoimmune diseases can be systemic or can affect specific organs and/or body systems. Their aetiology is multifactorial, involving both genetic and environmental factors. Likewise, the aetiology of headaches and specifically of migraine is accepted as being multifactorial.

Polymorphisms of genes encoding for human leukocyte antigens (HLA) and cytokines are considered risk factors for autoimmune disorders. Some studies have found that the same genes are involved in migraine pathogenesis $[27,28]$. These findings suggest that a common genetic background renders patients more susceptible to both migraine and immunological disorders and that some immunological alterations, for instance changes in inflammatory cytokines levels, may have a role in migraine pathophysiology.

In this regard, a significant increase in the peripheral levels of pro-inflammatory cytokines such TNF- $\alpha$, IL- $1 \beta$, IL-6 and IL-8-whose involvement in many autoimmune disorders is well known-have been found in migraine patients, both in interictal and ictal periods [29-32]. The increase of the above cytokines and chemokines in migraine, especially between attacks, suggests a proinflammatory status underlying migraine regardless of the acute phase of the disease, which could possibly explain an association between migraine and some inflammatory/autoimmune diseases.

The increase of IL-10 levels observed during an attack in some studies [33-35] has been interpreted as a compensatory mechanism aimed to antagonize pro-inflammatory cytokines during the ictal period, by exerting anti-nociceptive effects and limiting neurogenic inflammation. This antiinflammatory cytokine plays a pivotal role also in immune regulation and therefore may prevent immunological/autoimmune disease onset and progression [36, 37].

Like in several autoimmune diseases, an impairment in natural killer (NK) cells, as well as a significant increase in the CD4+ lymphocyte and a decrease in the CD8+ lymphocyte subsets, was observed in migraine patients [38-41]. Changes in CD4+ and CD8+ lymphocyte subsets were associated with a reduction of the immunoregulatory $\mathrm{CD} 4+\mathrm{CD} 25+$ cell levels in migraineurs in a recent study, suggesting that the failure of selfrecognition mechanisms might play a role in migraine pathogenesis and predispose migraineurs to immunological/autoimmune disorders [42].

Theoretically, the prevalence of pro-inflammatory cytokines over anti-inflammatory mediators, as well as dysregulation of lymphocyte subsets in migraine, could furnish another pathophysiological explanation of the potential link between this primary headache and immunological disorders. 
Even for cluster headache $(\mathrm{CH})$, some evidence supports a role for immunological dysfunctions in the pathogenesis of this disorder. Dated findings in cluster headache include a negative association with HLA-B14, the increase in NK cytotoxicity, the augmented receptor expression of classical neurotransmitters of pain-such serotonin or histamine-on immunocompetent cells, and the increase in the levels of cytokines with a potent pro-inflammatory activity such as IL-1 $\beta$ [43]. Based on these observations, a robust association between $\mathrm{CH}$ and immunological disorders would have been expected. However, a study including $27 \mathrm{CH}$ patients and 99 healthy controls failed to detect a higher prevalence of systemic inflammatory diseases in the $\mathrm{CH}$ group compared to controls, examining both laboratory and clinical data [44].

Little is known in the role of a derangement of the immune system in tension-type headache (TTH). Research in this regard revealed an increase in peripheral levels of IL-8 [45], IL- 6 [46] and IL-1 $ß$ [47] and an increase in IL-1ra and monocyte chemoattractant protein-1 levels in the cerebrospinal fluid (CSF) [48]. Starting from these observations, one could speculate that pro-inflammatory cytokines might be associated with pain by their direct binding to receptors on afferent neurons, including peripheral myofascial nociceptors that are thought to be crucial in TTH. The activation of nociceptors by cytokines, in turn, appears to be able to generate action potentials, thus inducing pain hypersensitivity [49].

In conclusion, the plausible role of immunological mechanisms in the pathogenesis of primary headaches, and particularly of migraine, has been consequently suggested to represent a potential link between headache and some immunological/autoimmune disorders. Below, we will summarize the available evidence on the possible association between headache and each specific immunological/autoimmune disease, considering both epidemiological and pathophysiological aspects.

\section{Headache and multiple sclerosis}

Multiple sclerosis (MS) is the most frequent immunemediated inflammatory disease of the CNS, causing myelin loss and axonal pathology at variable degrees, therein generally leading to progressive neurological dysfunction and disability [50,51]. Headache and migraine are common features in MS. Their occurrence can influence MS treatment and significantly impair the quality of life of patients due to related disabilities $[52,53]$.

\section{Epidemiological evidence}

The first association between MS and headache was described in 1960 [54, 55]. Subsequently, several studies assessed the prevalence of migraine and TTH in MS patients and reported rates between 2 and 67\% for migraine [56-74] and between 12.2 and 55\% for tensiontype headache (TTH) [61, 67]. This latter primary headache seems to occur more frequently in progressive form of MS. [61] Particularly for migraine, the occurrence was considerably higher in females. Furthermore, available evidence supports a bidirectional relationship between migraine and MS, highlighting the role of migraine as potential risk factor for MS. [75, 76]

The most relevant results of studies on the prevalence of headache in MS patients are shown in Table 1. The variability of the results in this regard can be in part attributed to the different criteria used for both MS and headache. Interestingly, in some of these studies, headache appeared to be correlated to MS subtypes [61, 67].

Based on previous published researches, a metaanalysis by Pakpoor et al. including 8 studies, for a total of 1,864 MS patients and 261,563 control cases, reported a significant association between migraine -including both MA and migraine without aura (MwA) subtypesand MS (OR $=2.60,95 \%$ CI 1.12-6.04), although with a significant heterogeneity [77]. However, when only MwA was considered, sensitivity analysis evidenced a significant association between this subtype of migraine and MS with an OR $=2.29$ without a significant heterogeneity. A more recent meta-analysis including 11 articles and 12 abstracts conference papers found a pooled prevalence of migraine of $31.1 \%$ in a total of $11,372 \mathrm{MS}$ cases, with a large variability among residents of different countries in the world [78].

Only one study specifically investigated a possible relationship between migraine and MS disease activity and observed that the migraine status in MS patients was significantly associated with a more symptomatic course of the disease, but not with a higher disability score or $\mathrm{T} 2$ lesion burden on brain magnetic resonance imaging (MRI) [62].

Additionally, other studies explored the occurrence of migraine or headache before MS diagnosis. One of these revealed the presence of headaches in $2 / 3$ of patients before MS onset, half of them with a family history of headaches unrelated to familiar MS occurrence. Remarkably, aura was diagnosed in $64 \%$ of the patients with no prior history of headache until MS onset, and in $34 \%$ of the patients with a prior history of headache. In addition, patients who reported auras were more likely to complain of a worsening of headache during MS exacerbation [52].

Likewise, a prospective, multicentre investigation involving 50 patients with the diagnosis of clinically isolated syndrome (CIS) or MS, screened using a specific headache questionnaire, reported headache within the last 4 weeks in $78 \%$ of cases, with migrainous features in $50 \%$. Interestingly, in the context of the first manifestation of MS, headache, especially with migrainous 


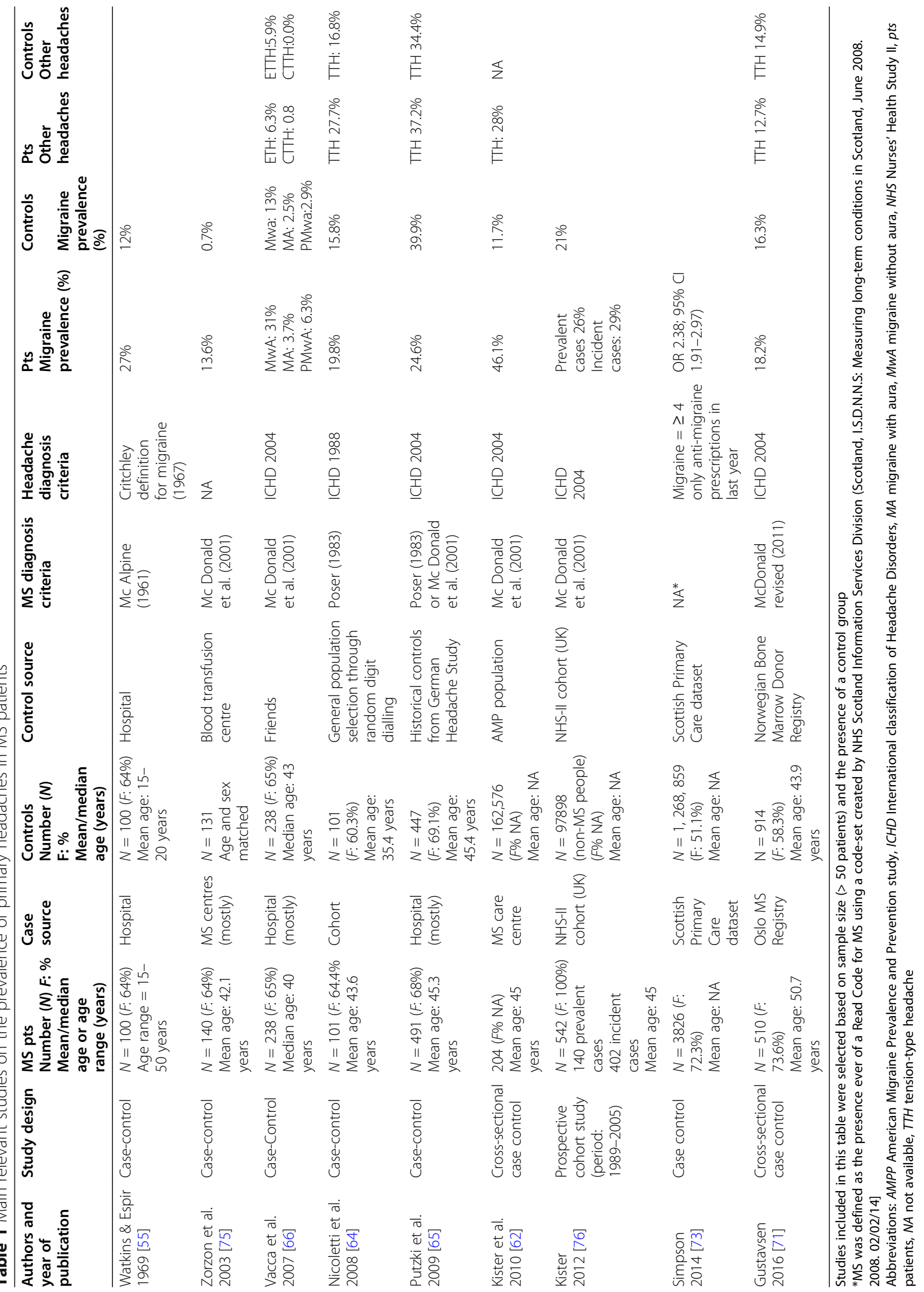


features, was more frequent than other symptoms or signs such as paresis, paraesthesia and hyperesthesia, optic neuritis, and brainstem or cerebellar signs. In this study, however, the lack of an appropriate control group did not allow for a definite conclusion on this high prevalence rate [79].

Indeed, based on published radiologically isolated syndrome (RIS) cohort studies, headache is by far the most common reason for performing MRI [80].

According to some authors, when MRI is performed specifically for headache and it evidences white matter (WM) lesions suggestive for MS, headache should be considered the first clinical manifestation of this inflammatory-demyelinating syndrome and accordingly screened. In particular, Gebhardt et al. suggested that patients with only headache and typical MS lesions could be classified as CIS or early MS, instead of RIS, and therefore could be treated with an immunomodulatory therapy, especially whenever new lesions are evidenced at neuro-radiological follow-up, even in the absence of clinical manifestations [79].

\section{Pathophysiological mechanisms}

Some hypotheses can be advocated to explain the occurrence of headache and particularly migraine in MS.

Trigemino-vascular activation at the meningeal vessels is characterized by neuroinflammation at several sites of the trigeminal pathway, including meningeal vasculature, TG, TNC and subcortical cortical regions involved in head pain processing. Meningeal inflammation in MS, by causing the release of several pro-inflammatory cytokines, chemokines and end-products, such as nitric oxide, might provide a pathophysiological explanation for the high migraine prevalence in MS and its exacerbation during relapse [81]. This has been supported by evidence from post-mortem histological analyses of MS patient brains of both lymphoid follicle-like structures in the cerebral meninges and diffused meningeal inflammation related to the degrees of both microglial activation and grey matter cortical demyelination [82] (see Fig. 1). However, this finding was obtained from tissue blocks and whole coronal macro sections from a wide array of brain areas of secondary progressive MS patients, who, in epidemiological studies, more often refer headache with tension-type features, rather than with migraine-like ones. However, it cannot be excluded that meningeal inflammation was more relevant in MS patients in $R R$ form particularly during relapse, but evidence in this regard is lacking at this time [81]. It cannot be excluded also that circulating pro-inflammatory cytokines or pro-inflammatory cytokines in CSF could contribute to the induction of headache with migraine-like features, but again, no studies are currently available in this regard.

Other mechanisms are deemed to be involved in the association between headache and specifically migraine and MS pathogenesis, such as a decrease in the CSF serotonin levels, a sympathetic hypofunction, and vitamin D deficiency [83, 84].

A further explanation for the occurrence of migraine de novo or the exacerbation of a pre-existing migraine is the location of lesions in strategic sites within the pathways involved in the processing of head pain. The relevance of demyelinating lesion location for the cooccurrence of MS and migraine have been supported by Gee et al. who reported that patients with at least a demyelinating lesion within the midbrain/periaqueductal grey (PAG) matter areas had a fourfold increase in migraine-like headaches, compared to MS patients without a lesion in these areas. This finding could be explained by the role attributed to PAG in the pathophysiology of migraine [85]. Conversely, the C2 location of demyelinating lesions has been associated with headache with tension-type features [65].

In the context of trigeminal neuralgia (TN), an underlying condition can be represented by an inflammatory lesion in the pons, even in patients without a definite diagnosis of MS. [86, 87] Furthermore, a recent study reported that, in patients with TN secondary to MS (TNMS), differently from patients with TN without MS, neurovascular contact does not play a significant role in the aetiology of pain. Indeed, in TN-MS the primary cause seems to be demyelination along the intra-pontine trigeminal afferents. Therefore, the authors concluded that microvascular decompression should generally not be offered to TN-MS patients [88].

Likewise, a demyelinating lesion in the pons at the trigeminal nerve root entry zone might be responsible also for typical $\mathrm{CH}$ attacks, instead of a trigeminal neuralgic pain which more frequently occurs [89].

\section{Effect of disease-modifying treatment on headache/ migraine}

Disease-modifying treatment for MS can also influence migraine course in MS patients affected. Some studies in this context evidenced that interferon- $\beta$ (IFN- $\beta$ ) seems to exacerbate migraine in MS patients who had already been suffering from this primary headache or induce a de novo migraine in patients without a previous history of headache [90-92]. Headache referred by patients treated with IFN- $\beta$ has often migraine-like features and some of the patients compelling headache then develop medication-overuse headache and seek help from a physician due to the severity and frequency of headache [92]. Headache has also been reported as a side effect of fingolimod, teriflunomide and alentuzumab treatment, 


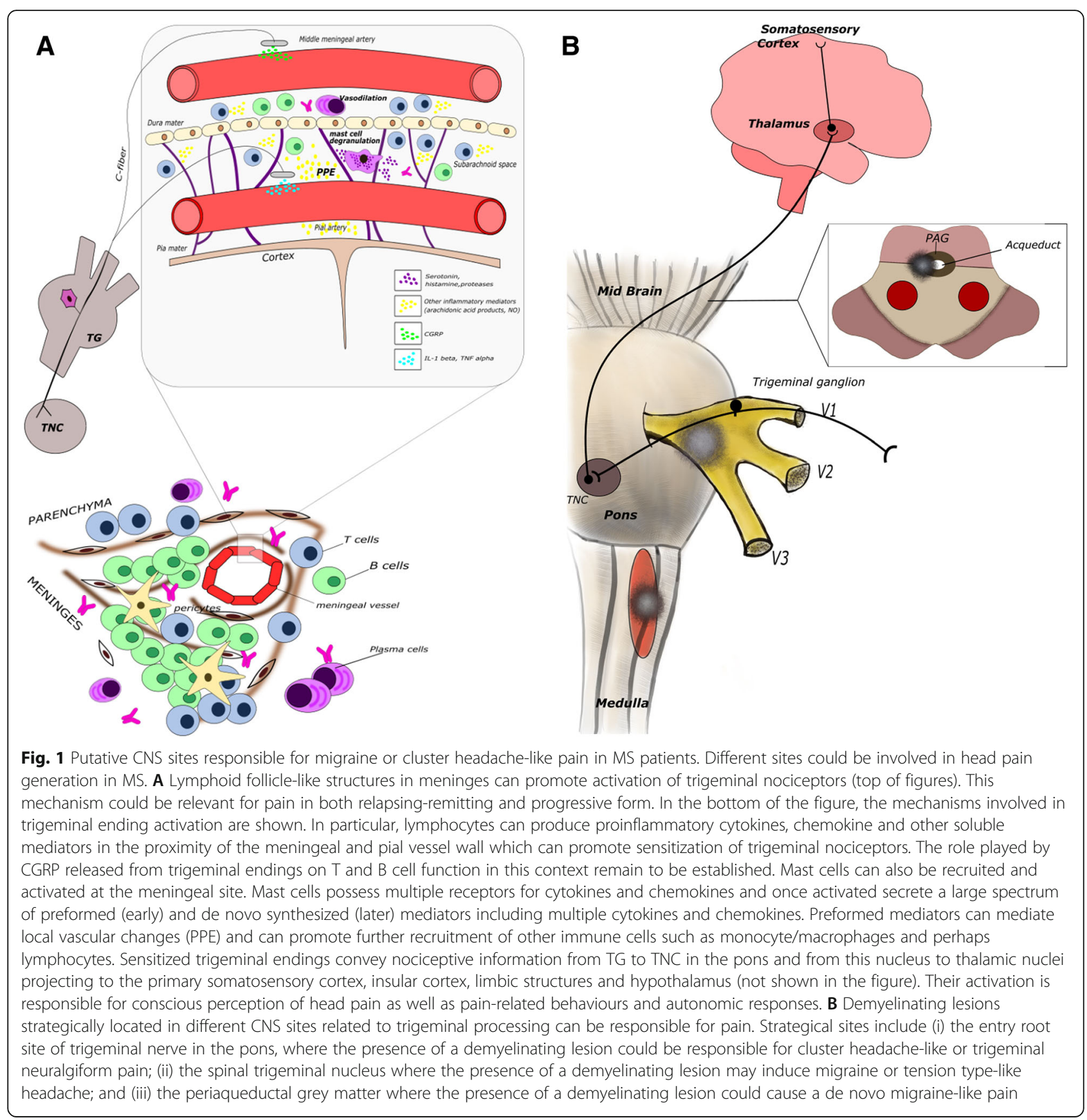

but reports from clinical trials investigating efficacy and safety on these immunomodulatory/immunosuppressive agents did not clarify the clinical characteristics of headache referred by patients $[68,93,94]$. Conversely, a longitudinal analysis of MS patients cohort revealed a significant reduction in migraine frequency for the subgroup of patients who were switched from IFN- $\beta$ to natalizumab, irrespective of their level of fatigue, anxiety, depression, alexithymia or other clinical variables as well as Migraine Disability Assessment questionnaire scores $[95,96]$. Headache is also rarely referred during dimethyl fumarate treatment [97]. It is noteworthy in this regard the evidence that this medication, when delivered via intraperitoneal injection in an animal model of nitroglycerin-induced migraine, exerts a protective effect on central sensitization by nuclear factors, including erythroid2-related factor (NRF2 ) [98]. These latter findings suggest that, among first-line therapies, dimethyl fumarate might offer relief for patients with both migraine and MS. 


\section{Management of headache in MS patients}

Management of headache and specifically of migraine in MS patients should be based on a combination of pharmacological and non-pharmacological approaches, as in the non-MS population. Specifically, migraine attacks can effectively be treated with triptans or non-steroidal anti-inflammatory drugs. Preventive drugs should be carefully selected taking into account their known efficacy/side effect profiles as well as any patient comorbidities. Patients with MS and headache should be instructed on the risk of symptomatic drug overuse, stressful conditions which can trigger attacks, and how to achieve more regular sleeping patterns. The presence of depression and/or anxiety in MS patients with headache significantly impair quality of life and it should be incorporated into the overall patient management [99].

Anti-CGRP and anti-CGRP receptor antibodies are the first tailored treatment for migraine and have been approved for the preventive treatment of highfrequency episodic migraine and chronic migraine [100]. Furthermore, CGRP antagonists are under evaluation for their symptomatic and prophylactic use in migraine [101].

One of the debated issue at this time is the use of these novel therapeutic strategies for migraine in patients affected by autoimmune diseases, specifically MS. [102]

Whether experimental evidence supports the role of CGRP as a potent trigger of acute neuorinflammation, its chronic tonic release, on the other hand, seems to exert immunomodulatory and anti inflammatory effects, by inhibiting innate immune response and limiting tissue damage [103]. Furthermore, this neuropeptide is strongly involved in host surveillance [104].

Prolonged antagonism of CGRP might therefore lead to a pro-inflammatory state or facilitate viral, bacterial and parasitic infections. However, the impact of blockade of CGRP on the overall immune balance at the moment is difficult to forecast. Thus, CGRP-blocking therapeutics should be carefully considered when used in patients with autoimmune diseases, such as MS, and close patient monitoring is recommended.

\section{Final remarks}

Taken together, the above epidemiological findings support an association between headache, and in particular migraine with MS, already at its onset or immediately before and during the course of disease, especially in the relapsing-remitting phase of the disease. Pathophysiological mechanisms above reported furnish a potential explanation of this association but some of them, such as the implication of meningeal inflammation, need to be confirmed in future research.

\section{Headache and vasculitides}

Vasculitides include a wide group of complex immunological diseases characterized by a relevant inflammation of blood vessel walls. An association between headache and vasculitides has not been definitely established, with some relevant exceptions. Of these, headache is considered a core symptom of giant cell arteritis (GCA). Furthermore, some evidence supports a correlation between headache and primary angiitis of the central nervous system (PACNS) [105]. Systemic vasculitides can also cause secondary headache, and Beh et's syndrome seems to be one of the most strongly associated with headache [106]. From a pathophysiological point of view, vasculitides leading to headache can affect the blood vessels that either irrigate the brain and meninges, or drain blood from these structures; both favour the release of CGRP and pro-inflammatory cytokines responsible for headache.

\section{Giant cell arteritis Epidemiological evidence}

Headache in GCA occurs at least over $70-80 \%$ of the time of disease and is typically severe. It may be unilateral or bilateral and is usually located in the temporal areas. Patients often describe the pain as sharp or burning, constant and severe and refractory to analgesia [107, 108]. Headache belongs to the category of symptoms due to the involvement of cranial vessels, followed by jaw claudication (pain on chewing), scalp tenderness, loss of vision and abnormalities of the temporal artery (pain on palpation, nodules, absence of pulse) [107-109]. Being so, headache is considered the most common symptom referred by GCA patients and the American College of Rheumatology include it among the diagnostic criteria of GCA (1990).

\section{Pathophysiological mechanisms}

GCA is a vasculitis targeting medium- and large-size arteries and is characterized by an inflammatory cellular infiltrate mainly $\mathrm{CD} 4+\mathrm{T}$ cells and macrophages with giant cells in the media and interruption of the elastic lamina of vessels involved. The typical lesions, granulomas in the vessel wall, are formed by CD4+ T cells, which undergo in situ activation in the adventitia, where they interact with indigenous dendritic cells. Tissue injury is mediated by several distinct sets of macrophages that are committed to diverse effector functions [110]. The first studies investigating cytokine expression by patient's temporal artery biopsies demonstrated an increased expression of IL-1, IL-2, IL-6, TGF-1 and IFN- $\gamma$ [111]. Cytokines, such as Il-1ß, TNF- $\alpha$ and IFN- $\gamma$ are the main inducers of adhesion molecule expression and are released from endothelial cells and from activated 
lymphocytes and macrophages [112]. Finally, the altered distribution of B cells in GCA has been related to CGA pathogenesis via the enhancement of IL-6 response [113]. Taken together, these immunological alterations may induce neuroinflammation and subsequently headache.

\section{Primary angiitis of the central nervous system Epidemiological evidence}

PACNS is a rare form of vasculitis with an estimated annual incidence rate of 2.4 cases per 1 million person-years. In a retrospective study of 101 patients with PACNS, the median age at the diagnosis was 47 years and $50 \%$ of patients were between 37 and 59 years at diagnosis [114]. Headache in PACNS can be moderate or severe at onset, having a chronic course ab initio or significantly worse over time. The characteristics and location of headache, are non-specific, like in many other forms of CNS vasculitis. Neck pain can be also associated.

Whenever there is suspicion of PACNS, reversible cerebral vasoconstriction syndrome (RCVS) should be excluded. PACNS and RCSV are frequently grouped together, given their shared clinical and radiological features. Headache is present in upwards of $60 \%$ of patients with PACNS and almost $100 \%$ in $\operatorname{RCVS}[115,116]$. In PACNS, headache is the most common symptom, followed by altered cognition and persistent neurologic deficits [117-119], while RCVS typically presents with acute onset of thunderclap headache with or without other neurologic symptoms [120]. Differential diagnosis between 'true' vasculitides and RCVS is pivotal, because the current anti-inflammatory medications used for the treatment of vasculitides can worsen the course of RCVS [105].

\section{Pathophysiological mechanisms}

Typical histopathologic features in PACNS are multifocal eosinophilic vascular infiltrates and necrotizing arterial wall damage, without evidence of amyloid deposition [121]. A granulomatous pattern was seen in $50 \%$ of a review of surgical biopsies [122]. Vessel alterations and inflammatory products from infiltrating cells can induce activation of nociceptive trigeminal endings distributing to brain vessels and can be responsible for headache. Less common complications, including ischemic strokes consequent to vascular thrombosis and intracerebral haemorrhage, can also be responsible for a new-onset headache, sometimes with the characteristics of thunderclap headache [123].

\section{Behçet's syndrome}

Behçet's syndrome is a systemic vasculitis where thrombosis or thrombophlebitis involves small and large veins while arterial involvement is less frequent.

\section{Epidemiological evidence}

With regard to Behçet's syndrome, a study conducted by Kidd [106] on an unselected group of patients reported a high prevalence of headache $(85.2 \%)$ with most of them suffering from headaches meeting the International Classification of Headache Disorders (ICHD) criteria for migraine. Moreover, the prevalence of visual or sensory aura was higher than that recorded in the general population of migraine suffers. The reason for this high prevalence of headache in patients with Beh et's syndrome is not fully understood.

\section{Pathophysiological mechanisms}

From a pathophysiological point of view, Behçet's syndrome can be considered a systemic 'vasculitis/perivasculitis'. In this context, pro-coagulant factors, such as tissue factor, fibrinogen, thrombin and protein $\mathrm{C}$, are believed to cause systemic inflammation and thrombus formation. Reactive oxygen species (ROS)-derived modifications also contribute to vascular structural and functional changes [124].

In CNS involvement by Behçet's syndrome, a clear typical vasculitis is uncommon [125], while the most frequent abnormality is represented by a marked perivascular cuffing of mononuclear cells, in particular $\mathrm{T}$ lymphocytes and monocytes, surrounding the small vessels [126]. In this case, microthrombotic mechanisms as well as oxidative stress might perhaps play an underlying role in fostering headache onset via activation of trigeminal nociceptive fibres distributing to affected small vessels [106, 127]. More difficult is to try to explain headache occurrence in patients with Behçet's syndrome without any clinical and radiological signs of CNS involvement. In this regard, it can be hypothesized that an enhanced inflammatory response, and the systemic overexpression of pro-inflammatory cytokines, in particular TNF- $\alpha$, can contribute to the sensitization of trigeminal nociceptors like in other systemic inflammatory diseases [128], but data in this field are still lacking.

\section{Other types of vasculitides Epidemiological evidence}

Other types of vasculitides, including polyarteritis nodosa (PAN) and Takayasu's arteritis (TAKA), can also involve CNS, resulting in cerebral infarctions and both intracerebral and subarachnoid haemorrhages, all of which may be responsible for secondary headaches [105]. TAKA is a large vessel vasculitis which typically affects young females. Headache usually occurs in the chronic phase of disease while it is rare in children [129]. In a recent case series of 67 patients with TAKA, 42.9\% had neurological involvement and dizziness was the most common neurological complaint (74\%) 
followed by visual disturbances (59.3\%) and headache (55.6\%) [130].

PAN typically affects medium vessel walls and is characterized by the formation of arterial pseudoaneurysms formed by erosion of the arterial walls via a necrotizing process. Neurological involvement most commonly presents with peripheral neuropathy as multiplex mononeuropathy and, less frequently, with CNS involvement. Ten percent of patients with PAN are at risk of ischemic strokes and cerebral haemorrhages [131]. Headache occurs in about $35 \%$ of PAN patients. It usually is referred later in the disease course, but sometimes, it is associated with early stages with core symptoms. PAN can mimic GCA, with headache and/or jaw claudication [132-134]. In a study on 27 patients with systemic necrotizing vasculitis and temporal artery biopsy localized vasculitis, Genereau et al. found that 22 of them (81\%) had cephalic symptoms including jaw claudication (33\%). Four patients who had temporal artery biopsy involvement led to an initial misdiagnosis of GCA, but later developed systemic symptoms that revealed the correct diagnosis of PAN [135].

Finally, small vessel vasculitides, such as Churg-Strauss Syndrome, Wegener Granulomatosis and microscopic polyangitis, are generally accompanied by polyneuropathy. CNS involvement in these diseases is rare, and their association with headache has not been well established.

\section{Pathophysiological mechanisms}

TAKA is a large vessel vasculitis characterized by a relevant infiltration of pro-inflammatory $\mathrm{T}$ cells in the vessel wall [136]. Abnormal immunity may play a pivotal role in its pathogenesis [137-139]. A recent transcriptome analysis in TAKA patients demonstrated a dysregulation of several genes in CD4+ and CD8+ samples compared to controls. Among these dysregulated genes, the most relevant included JAK/STAT and cytokine/chemokinerelated signalling which therefore might be a promising target for treatment [140]. Headache as well as dizziness in TAKA has been attributed to the involvement of the vertebral artery, which in turn activates head nociceptive input to the brain [141]. In addition, it has been hypothesized that hypertension due to renal artery involvement especially observed in young patients may play a role in headache occurrence $[142,143]$

\section{Final remarks}

Headache is a common finding in vasculitides and probably recognizes pathophysiological mechanisms specific for each of them. These mechanisms, however, are still not clear and need to be further investigated in the next years.

\section{Headache and connectivitis}

\section{Systemic lupus erythematosus}

Systemic lupus erythematosus (SLE) is a chronic systemic autoimmune disease, affecting the joints and multiple organs including the skin, heart, lungs, kidneys and nervous system. Neurological involvement-central, peripheral and autonomic nervous system-and psychiatric events in SLE is a subcategory termed 'neuropsychiatric lupus' (NPSLE) [144].

\section{Epidemiological evidence}

Neuropsychiatric symptoms affect about half of the patients with SLE over the course of disease. Their spectrum can vary from mild to severe and therein can negatively influence the prognosis of the disease, as they are a relevant cause of morbility and mortality [145].

Neuropsychiatric symptoms can also be among the earliest manifestations of SLE; indeed some reports have suggested that up to $40 \%$ of these symptoms appear during the first year from SLE diagnosis [146]. Caucasian ethnicity and older age are reported to be associated with shorter time to neuropsychiatric damage $[147,148]$.

The most frequent SLE manifestations of CNS involvement include headache, mood disorders and cognitive dysfunction, followed by stroke and seizures [144]. Specifically, headache has been reported as the most frequent symptom of NPSLE. Headache in some cases may present features suggestive of an underlying organic cause and these can include high severity, concomitant with other neurological symptoms, abnormal laboratory results, as well as a better response to corticosteroids compared to other currently available treatments.

The role of headache in SLE has been recognized by the inclusion in the SLE Disease Activity Index (SLEDAI) of 'lupus headache' as a descriptor, defined as a severe, persistent headache which is often of migraine type and unresponsive to analgesia [149]. In light of this, when the third edition of the ICHD-3 is considered, it would appear that the 'lupus headache' could be allocated to various headache subtypes, depending on additional clinical features, including new daily persistent headache, high-frequency episodic migraine or chronic migraine with or without medication overuse.

Several epidemiological studies have been performed over the last two decades evidencing a broad range of variability in the prevalence of headache and specifically migraine in SLE [150-165]. In Table 2, findings from studies on the prevalence of headache in SLE patients are summarized.

Like in MS, discrepancies regarding prevalence results are most likely due to differences in study designs, study populations and methodological approaches, as well as the differing definitions of headache and headache subtypes adopted and, in some cases, the lack of control 


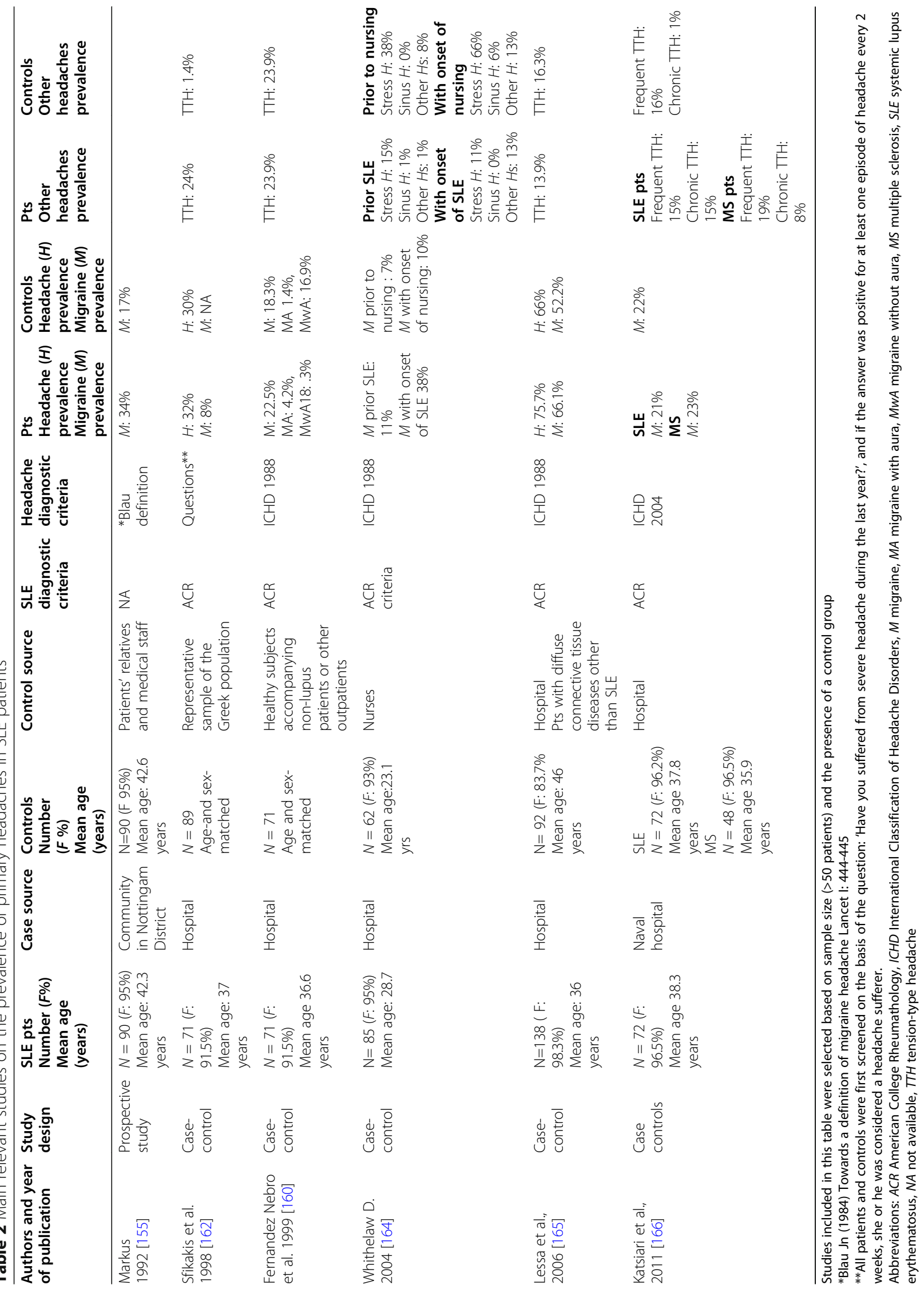


groups. Some authors described MA with a high frequency in patients with SLE [163], but other studies have not confirmed this finding [154, 160, 165].

Concerning TTH in patients with SLE, some investigations have revealed a higher prevalence of TTH compared to migraine [162, 167]; in additional studies, however, either an equal $[154,155,158,160,168]$ or higher $[156,161,163,169]$ prevalence of migraine compared with TTH was observed.

In 2004, results of a meta-analysis by Mitsikostas et al. did not find any differences in headache prevalence between controls and SLE patients, when considering the total population of SLE patients, with and without neuropsychiatric manifestations [170]. In agreement with this, a 2011 study by Katsiari et al. observed a similar prevalence of migraine (MA and MwA), among SLE patients (21\%), MS patients (23\%), and controls (22\%). However, in this study, the duration and severity of migraine attacks were milder in SLE patients compared to controls. Only chronic TTH was significantly more prevalent in SLE patients (12.5\%) compared to controls (1.4\%). Furthermore, either in SLE or MS patient groups, no associations between any headache type and clinical manifestations, autoantibodies or disease activity were found [166].

In 2011, Unterman et al. [146] published a metaanalysis that specifically investigated the prevalence of neuropsychiatric manifestations in SLE. The authors found a $12.2 \%$ prevalence of headache in the pooled cohort and $23.3 \%$ (28.3\% in a random-effects model) when only prospective studies were considered. These results are therefore in apparent disagreement with those by Mitsikostas et al. who reported a $50.2 \%$ prevalence in the pooled group of SLE patients. This finding is worthy of some consideration. The low prevalence of headache in Unterman et al.'s meta-analysis can be explained by the inclusion of a large Asian population who are known to report a lower prevalence of headache. Another factor of inhomogeneity of the results is the inclusion in Unterman et al.'s meta-analysis of both studies with a retrospective and prospective design with lower prevalence of headache in retrospective chart-driven studies; patients in these latter studies account for 3008/5057 patients in the entire cohort. Indeed, when analysing the prevalence of headache only in prospective studies excluding one on Chinese subjects and one where headache was not recorded, Unterman et al. calculated a 37\% estimated prevalence using a random-effects model, a result which is much closer to the $50.2 \%$ prevalence found by Mitsikostas et al. Notably, a similar prevalence $(52 \%)$ was found also by a recent meta-analysis involving paediatric SLE populations [171].

In line with the evidence of a higher estimated prevalence of headache in prospective studies than in retrospective ones (especially when the former imply longer follow-up), Hanly et al. in a prospective international inception cohort study, involving 1732 SLE patients, found at the baseline $17.8 \%$ of patients with headache $(60.7 \%$, migraine, $8.6 \%$, tension-type headache, $7.1 \%$, intractable non-specific headache, $2.6 \%$ : cluster headache and $1.0 \%$. intracranial hypertension), but the prevalence of headache increased to $58 \%$ after 10 years. In this study, only $1.5 \%$ of patients specifically met the criteria of lupus headache, as identified in the SLEDAI [172].

\section{Studies evaluating the association between headache and SLE activity}

In the context of research investigating the association between headache and SLE activity, a study carried out by Markus and Hopkinson evidenced a close temporal relationship between the onset of both headache and SLE in many patients and that both migraine and nonmigraine headaches often respond to specific SLE treatments [155]. In addition, Amit et al. observed that SLE patients experiencing moderate to severe headache on at least two consecutive encounters, additionally suffered from more severe joint pain, muscle pain, photosensitivity, mouth ulcers, fever and fatigue compared to SLE patients without headache. Patients with headache also had higher disease activity scores, and many of them showed CNS involvement [173].

Appenzeller and Costallat also revealed that SLE patients with active migraine had higher SLEDAI scores compared with those without. The authors went on to state that SLE patients with a history of migraine had also significantly higher cumulative organ damage scores compared to SLE patients without. Furthermore, active migraine was associated with higher levels of antiphospholipid antibodies and worsening of Raynaud's phenomenon [174]. In contrast with the above results, other studies were not able to verify an association among disease activity (i.e. SLEDAI-2K scores with or without lupus headache), damage scores (i.e. Systemic Lupus International Collaborating Clinics (SLICC)/American College of Rheumatology Damage Index-SDI scores), use of corticosteroids or antimalarials or immunosuppressive medications, and either occurrence or frequency of headache with particular regard to migraine. In most cases, headache has been reported to be unrelated to other SLE manifestations and has its own independent course, which is generally recurrent or chronic [166, 170, 172].

Based on these conflicting findings, lupus headache was not included in the American College of Rheumatology Ad Hoc Committee definition of neuropsychiatric syndrome in SLE. 


\section{Pathophysiological mechanisms}

The pathogenic mechanisms of NPSLE and 'lupus headache' remain to be elucidated. Numerous autoantibodies have been detected in plasma samples of SLE patients and have been linked to NPSLE. They include anti-ribosomal-P, anti-DNA/NR2, anti-DNA (16-1 idiotype), antiphospholipid (aPL), anticardiolipin ( $\mathrm{aCL}$ ) and GABA antibodies $[175,176]$. It has been hypothesized that auto-antibodies or circulating pro-inflammatory cytokines/chemokines cross the blood-brain barrier (BBB), therein entering the brain and inducing neurotoxicity [177-180].

As part of research investigating autoantibodies profile, Hawro et al. reported that in NPSLE patients, the presence of autoantibodies to $\beta 2$ GPI were significantly associated with non-specific intractable headaches, ischemic stroke and seizures, and resulted having a better predictive value than either aCL or lupus anticoagulant (LA) [181].

Mechanisms possibly implicated in the pathogenesis of neuropsychiatric manifestations of SLE are complex. They involve genetic factors, vascular damage and occlusion, a BBB dysfunction, neuronal damage mediated by autoantibodies or inflammatory mediators including cytokines, and also a direct neuronal cell death [182]. Two relevant pathogenetic pathways have been identified: (i) a prevalent ischemic-vascular mechanism induced by aPL, immune complexes and leuko-agglutination involving large and small blood vessels, which is considered more frequently responsible for focal neuropsychiatric manifestations, and (ii) a predominantly inflammatoryneurotoxic mechanism mediated by complement activation, increased permeability of the BBB, intrathecal autoantibodies migration as well as local production of immune complexes and pro-inflammatory cytokines and other inflammatory mediators, which possibly account for neuropsychiatric diffuse manifestations.

However, if this latter mechanism could explain headache in some SLE patients remains to be established.

Findings on the specific clinical features and laboratory abnormalities associated with headache and migraine in the course of SLE are also inconsistent. CSF levels of different cytokines have been reported to be lower in SLE patients with migraine compared to SLE patients with other neuropsychiatric manifestations [183] and similar CSF IL-6 concentrations compared to controls. Even the levels of autoantibodies known to be involved in SLE were not clearly associated with headache $[150,156]$.

Neuroimaging studies based on MRI [184, 185], H1Magnetic resonance spectroscopy [186] and singlephoton emission computed tomography $[187,188]$ have been also performed in order to identify the anatomic and functional correlates underlying the possible association between SLE and headache. Unfortunately, these studies were not able to definitely clarify this issue due to the small sample size and in some cases the lack of a control group [188]. Furthermore, results of the above morphometric MRI, MRS and SPECT studies have not been replicated and therefore abnormalities detected could not be currently assumed as a specific flag of the association of headache and SLE.

\section{Final remarks}

A link between SLE and headache remains therefore controversial. Indeed, on one hand, headache is considered by many authors the most frequent neuropsychiatric manifestation of SLE, but on the other hand, the prevalence of headache in the total SLE population is overall similar to that observed in the general population. Furthermore, neither laboratory findings nor results of conventional and non-convention neuroimaging studies furnish specific and confirmed hallmarks supporting a clear association between these two conditions.

In addition, neuropsychological factors could also influence the occurrence of headache in SLE patients. These latter tended to present a high prevalence of anxiety and depression, suggesting that headache in SLE patients may, at least in part, be induced by emotional stress related to the clinical status [162, 175].

Therefore, based on the available evidence, in patients with SLE headache does not itself require further investigation, but should be classified according to IHS criteria and, in most cases, be managed as a primary headache.

\section{Primary Sjögren's syndrome}

Primary Sjögren's syndrome (pSS) is a chronic, autoimmune disease characterized by dryness of both the mouth and the eyes associated with the involvements of other exocrine glands, along with a multiplicity of organs and systems [189]. Mononuclear cell infiltrate and progressive injury of the exocrinee glands are the main pathological hallmarks of the disease. The direct etiopathogenetic roles of the antiRo (SSA and SSB) antibodies have been defined. The prevalence of the disease ranges between $1 \%$ and $3 \%$ in the general population (female/male ratio about 9:1 in the age group $40-50$ years) [190, 191]. When associated with other autoimmune rheumatic diseases, it is defined as secondary Sjögren's syndrome (sSS), representing $30 \%$ of cases.

\section{Epidemiological evidence}

Several epidemiological studies, as well as pathophysiological and histopathological research, have emphasized the involvement of the Peripheral Nervous System in Sjogren's syndrome (SS), whereas the CNS involvement has not been fully defined. Since the first observation in 1982 by Alexander et al. of focal or diffuse symptoms 
suggesting CNS involvement, later studies have been performed to investigate the possible occurrence of neuropsychiatric syndromes also in seronegative forms of SS [192-194].

Since the adoption of the current diagnostic criteria for SS in 2002 [195], little agreement has been reached regarding the prevalence of CNS signs and symptoms, ranging from 2.5 to $60 \%$ [196-199]. This variability may be influenced by the lack of a universally shared definition of CNS involvement in primary Sjögren's syndrome (pSS). Moreover, neurological onset may sometimes precede both the clinical appearance of systemic symptoms and the immunological diagnosis by many years [200]. Thus, a pSS should always be considered in patients with relatively non-specific neurological symptoms, such as headaches, associated with sicca syndrome [201]. Among CNS manifestations of pSS, headache seems to be one of the most common. According to a study by Morreale et al. [196], the most frequent type of headache observed in a cohort of pSS patients fulfilled ICHD-II criteria for MwoA, while TTH subtypes and chronic or medication overuse complications were less frequent.

Other epidemiological studies have not well established a relationship between headache and SS. While some of them reported a significantly higher prevalence of migraine in patients with pSS compared to controls [202, 203], in contrast a population-based retrospective cohort study did not evidence any difference in the prevalence of migraine between patients and controls. In this latter study, chronic TTH was the only form of headache which resulted more commonly in pSS patients when compared to healthy subjects. However, chronic TTH was not associated with pSS-related autoantibodies, fatigue, depression, abnormalities on MRI or abnormalities in the cerebrospinal fluid. Higher depression and fatigue scores emerged in patients with pSS, but they were not associated with headache [204].

Some researchers have also investigated the presence of dry eye in migraine patients. In particular, Koktekir et al. found significantly lower tear function test scores for migraine patients, compared to controls. However, the authors did not assess the correlation between dry eye severity and migraine pain scores [205]. Celikbilek and Adam revealed that the presence of dry eye was higher in migraine patients compared to normal controls, but the difference did not reach statistical significance. They also reported a higher prevalence of MA and longer duration of attacks in migraine patients with dry eye [206]. More recently, Sarac et al. observed a higher prevalence of dry eye in 50 migraine patients compared to age- and sexmatched healthy subjects. The authors speculated that dryness of the ocular surface may activate the trigeminal nerve to cause reflex lacrimation, and the activation of the trigeminal nerve may trigger migraine headache [207].

\section{Pathophysiological mechanisms}

Mononuclear cell infiltration leading to a progressive injury of the exocrine glands is the main pathophysiological feature of pSS. Immuno-mediated mechanisms (especially an anti-Ro/SSA-mediated small vessel vasculitis) can also involve the $\mathrm{CNS}$ and can explain some clinical manifestations of the disease [208]. In particular, headache, cognitive dysfunction, mood disorders and fatigue referred by some patients suggest a higher diffused CNS compromission rather than focal involvement such as in MS-like clinical course or optic neuromyelitis-like syndrome [209].

In this regard, Escudero et al. proposed that migrainemimic headache in pSS could be a direct expression of the disorder and not a mere comorbidity, as suggested in the neuropsychiatric SLE [210].

In the study of Morreale et al [196], .MwoA occurrence resulted significantly related to SSA antibodies, MRS alterations (reduction of NAA levels or decrease in $\mathrm{NAA} / \mathrm{Cr}$ ratio) and hemodynamic dysfunction at ultrasonographic evaluation, but not to the presence of vasculitic brain lesions and/or macrovascular damage (such as WM lesions or MS-like lesions). In addition, the frequency of headache and alterations at MRS was higher in patients with Raynaud's phenomenon. According to the authors, these findings suggest a possible endothelial dysfunction of the cerebral microcirculation or a potential inflammation-mediated shift of the neurovascular coupling which possibly accounts for both headache (especially migraine) and Raynaud phenomenon. In other words, headache in pSS has been suggested to be related to an 'autoimmune endotheliitis' which directly alters biochemical and humoral markers, in turn inducing perivascular inflammation that fosters vasomotor dysfunction.

\section{Final remarks}

Headache is a frequent finding in pSS and probably recognizes a vascular inflammation and endothelium dysfunction at the basis of its induction.

\section{Scleroderma}

Nervous system involvement in scleroderma has been increasingly recognized and an association between migraine and systemic scleroderma (SSc) has been suggested.

\section{Epidemiological evidence}

In a 1978 study by Goldberg et al., SSc with typical migraine headache occurred in 16 well-documented cases observed over a 25-year period. In 13 of these, SSc developed after 15 years or more of therapy with ergot or methysergide preparations [211]. Based on these findings, the authors suggested caution when administrating 
these drugs for patients with migraine and more so in presence of signs of Raynaud's disease or early vascular SSc. In a more recent study including 182 case reports of patients with SSc and 50 diagnosed with localized scleroderma (LS), CNS involvement was observed in a sizeable proportion of patients. The most frequent symptom was headache (23.73\%), followed by seizures (13.56\%) and cognitive impairment (8.47\%). Depression and anxiety were also frequently observed $(73.15 \%$ and $23.95 \%$, respectively). In LS, seizures $(41.58 \%)$ and headache $(18.81 \%)$ were the most commonly reported symptoms [212].

Treatment of SSc with nervous system involvement is not yet standardized. However, corticosteroids and cyclophosphamide are usually prescribed in severe cases. The effect of these treatments on headache in SSc has not been investigated.

\section{Pathophysiological mechanisms}

No studies have been carried out investigating the mechanisms underlying the headache occurrence in scleroderma; therefore no conclusions can be drawn at the moment on this matter.

\section{Rheumatoid arthritis and other forms of chronic rheumatic disorders}

Rheumatoid arthritis (RA) is a chronic disease producing inflammatory synovitis in multiple joints.

\section{Epidemiological evidence}

This immunological disease seems to be more prevalent in patients with migraine. In a questionnaire survey of migraine patients in Denmark, the prevalence of RA was significantly higher in migraineurs compared to patients without migraine [213]. Another population-based study of headache patients in the USA reported that migraineurs were significantly more likely to suffer RA (OR 1.95, C.I.95\% 1.68-2.25) [214]. A recent study looked at whether patients who had migraine were more likely to later develop RA [215]. Nearly 58,000 patients with a diagnosis of migraine were compared with similar number of age- and sex-matched control subjects. During follow-up, 461 subjects in the migraine group in contrast with 220 in the non-migraine group developed RA. The incidence rate of RA was 3.18 per 1000 person-years in the migraine group and 1.54 per 1000 person-years in the non-migraine group. Furthermore, compared to the control group, the crude hazard ratio of RA for the migraine group was 2.15 and the multivariable-adjusted hazard ratio was 1.91 .

Of late, a link between headache and rheumatic disorders has also been investigated in the paediatric population. Specifically, a cross-sectional study assessed the presence, prevalence and clinical characteristics of primary headaches in 601 paediatric patients with chronic rheumatic diseases, such as juvenile idiopathic arthritis (JIA) and familial Mediterranean fever (FMF), using a semi-structured 53 item headache questionnaire. A higher prevalence of migraine (29.1\%) followed by TTH (13.8\%) in patients with paediatric JIA and FMF was documented. Among primary headaches, migraine and probable migraine were observed in $67.0 \%$ of FMF and $69.4 \%$ of JIA patients, while TTH was observed in $32.9 \%$ of FMF and $30.6 \%$ of JIA patients. Overall, onethird of these migraine patients had a family history of migraine in parents [216].

\section{Pathophysiological mechanisms}

It has been hypothesized that the association between migraine and RA might be due to a shared pathogenic mechanism; namely a dysfunction of the serotonergic system [193]. Indeed, serotonergic dysfunction has been implicated in the pathogeneses of both RA and migraine. In this regard, Zeller et al. observed that platelet serotonin levels were significantly decreased in RA patients and at the same time were inversely related to clinical RA activity [217]. Furthermore, Sacre et al. reported that serotonin reuptake inhibitors reduced the production of inflammatory cytokines in human RA synovial membrane cultures [218]. Another study suggested that the susceptibility for RA is related to genetic polymorphisms of the serotonin receptor 2A [219]. Likewise, impaired serotonin metabolism was evidenced in migraineurs, possibly triggering cranial vasoconstriction and neuronal sensitization [220]. Serotonin depletion has also been associated with increased cortical neuron sensitivity and enhanced vascular responses induced by CSD in an animal model of migraine [221]. As far as JIA is concerned, a small vessel disease has been suggested to underlie the clinical manifestations of JIA and may contribute to microvascular dysfunction causing migraine.

\section{Antiphospholipid syndrome}

Antiphospholipid syndrome (APS) is an autoimmune, pro-thrombotic, multisystem disorder characterized by the combination of several clinical manifestations including arterial and/or venous thrombosis, pregnancy complications and/or recurrent foetal loss, thrombocytopenia and the presence of persistently positive antiphospholipid antibodies (aPLs) [216, 222-224].

aPLs represent a diverse collection of autoantibodies, directed against membrane phospholipids, including lupus anticoagulant (LA), anti-b-2-glycoprotein I (b2GPI), prothrombin (PT) and cardiolipin antibodies (aCL). The principal targets for the aPLs are b2GPI and PT [225-227]. APS can be accompanied by additional clinical features, including valvular lesions, migraine, Raynaud's phenomenon, livedo reticularis, arterial hypertension and autonomic 
disturbances, such as postural tachycardia syndrome, neurocardiogenic syncope and orthostatic hypotension. In clinical practice, APS is classified as primary (PAPS) or secondary (SAPS), according to the absence or presence of another autoimmune disease, respectively [228].

\section{Epidemiological evidence}

Among neurological complications, recurrent headaches are quite prevalent in APS patients. Migraine is the most common type of headache and the most frequent neurological manifestation of APS [229], ranging from classic intermittent MA or MwA to unremitting, debilitating headache [230]. Furthermore, a study by Schofield et al. reported that migraine was the most common clinical, not only neurological, manifestation (87\%) whenever APS coexisted with different types of autonomic disorders [231].

Several studies investigated the prevalence of migraine in APS, detecting rates ranging between 0 and 30\% [232-243]. Later data from the Euro-Phospholipid Project revealed a $20 \%$ prevalence rate of migraine in APS patients [229]. More in detail, all the studies conducted on the European population with APS documented the co-existence of headache with LA and/or CL [244, 245], except one involving a group of Serbian patients [246]. According to a study by Hughes et al. APS patients report the onset of headache in their teenage years, then often disappears for 1 or 2 decades, only to reappear in their 3rd to 4th decade [247]. Transient ischemic attacks (TIAs) and visual or speech disturbances are accompanying symptoms in some patients, and often there is a strong family history of headaches $[245,246]$. Therefore, some authors have recommended screening for aPLs in patients known to have migraine or recurrent headaches, since there might be a link between migraine and stroke in APS patients [247-249].

A study carried out by Zhu et al. [250] on a cohort of 51 APS patients showed a higher prevalence of headache in those with neurological antiphospholipid syndrome (NAPS), when compared to the rheumatologic form of the disease (RAPS). Interestingly, the authors detected by digital subtraction angiography (DSA) in NAPS patients typically multifocal vascular stenoses. In particular, while gadolinium-enhanced MRI failed to detect any lesions, DSA clearly evidenced a bilateral lack of blood vessels in the parietal lobes of 9 patients.

Based on the observation of headache in patients with APS, further research focused on assessing the prevalence of APLs in migraineurs also in the absence of a clinical diagnosis of APS. Some studies on this matter reported a higher prevalence of aPLs in migraineurs, when compared to healthy controls [233, 237, 238], while others did not observe an association [236, 241, 251, 252]. This discrepancy has been challenged by a recent systematic review re-analysing 11 case-control studies published between 1991 and 2014. The authors found a significantly increased rate of APLs in migraineurs $(n=170 / 779,21.8 \%)$, when compared to healthy controls $(n=63 / 741,8.5 \%)(p<0.0001)$ [253].

\section{Pathophysiological mechanisms}

As far as the mechanisms underlying headache in APS, it can be speculated that circulating APLs may damage endothelium of the vessels resulting in active thrombogenesis and slow fibrinolysis [254]. Endothelium and vascular wall alterations in the dural vasculature as well as inflammatory reactions and products from aggregated platelets may be suitable triggers for meningeal trigeminal ending activation, which is responsible for headache in some patients. However, the exact mechanisms underlying this association have not still been clarified.

\section{Treatment considerations}

Headache associated with APS is often untreatable, poorly responsive to analgesics and/or narcotics and sometimes starts several years before the diagnosis of APS. Therapeutic strategies such as oral direct thrombin or anti-factor Xa inhibitors, hydroxychloroquine, statins, $\mathrm{B}$ cell inhibition, complement inhibition, and peptide therapy have been proposed for the management of thrombotic APS. However, a simple approach to prophylaxis against CNS complications of PAPS and SAPS is anticoagulation $[255,256]$. Indeed, heparin followed by long-term anticoagulation with warfarin remains the gold-standard treatment [257]. Specifically, anticoagulation can lead to a marked improvement or resolution of migraine in many cases $[258,259]$. Moreover, corticosteroids alone or in combination with anticoagulants and other therapies, including immunosuppressive regimens, might be a beneficial treatment option for both PAPS and SAPS patients with headache.

\section{Final remarks}

Headache is a frequent clinical manifestation of APS. The best management of this condition probably includes anti-inflammatory and anticoagulants drugs, but randomized controlled trials will be necessary in this field in the next years to definitely clarify this issue.

\section{Migraine and immuno-mediated endocrine disorders}

Studies investigating a possible relationship between immuno-mediated endocrine disorders and migraine are scarce and have prevailingly focused on type 1 diabetes mellitus (DM) and thyroid disorders. 


\section{Diabetes mellitus type 1 Epidemiological evidence}

Unlike other autoimmune diseases where a high prevalence of headache has been documented, a negative association between type $1 \mathrm{DM}$ and headache has emerged from population-based cross-sectional studies. In the Head Hunt Study, the OR of migraine was lower among patients with DM, compared to those without, being 0.4 for type $1 \mathrm{DM}$ and 0.7 for type $2 \mathrm{DM}$, respectively. In the same study, the prevalence of migraine among patients with diabetes varied depending on age, with a higher prevalence in younger age groups [260]. A more recent research specifically investigated for an association between type I DM and headache in particular migraine. From a multivariate analysis of 26,121 participants in 2 surveys, an OR of 0.55 emerged for headache and 0.47 for migraine, compared to those without DM after adjusting for age, gender, years of formal education, and smoking. Accordingly, the merged group of patients with type $1 \mathrm{DM}$ and latent autoimmune diabetes of adults had a lower risk of migraine (OR of 0.53). Similar results were obtained from a third survey including 39,584 participants. In contrast with findings from patients with type $1 \mathrm{DM}$, this survey reported no inverse association between headache and type 2 DM [261].

\section{Pathophysiological mechanisms}

Probably, changes in vascular reactivity and diabetic neuropathy, as well as insulin treatment, might be involved in the lower prevalence of migraine in patients with type $1 \mathrm{DM}$ [261]. Conversely, the lack of a clear inverse association between migraine and type $2 \mathrm{DM}$ might suggest an involvement of different genetic and environmental factors implicated in type 1 and type 2 diabetes.

\section{Hypothyroidism \\ Epidemiological evidence}

High frequencies of migraine in patients with either overt or subclinical hypothyroidism have been recorded. Accordingly, in a recent study, the lifetime prevalence of MA and MwA appeared to be significantly higher (46\%) in subclinical hypothyroidism patients recruited from an endocrine clinic, when compared to age- and sexmatched controls (13\%) with an OR $=5.80(95 \% \mathrm{CI}$ 3.35-10.34). No differences in the levels of thyroid hormones and antibodies emerged between patients with subclinical hypothyroidism with migraine and those without. Noteworthy, an increased risk of developing other autoimmune diseases was noted in patients presenting both subclinical hypothyroidism and migraine, when compared to patients with subclinical hypothyroidism without migraine [262]. Furthermore, young migraineurs had an increased risk of developing subclinical hypothyroidism; likewise, adult headache patients, in particular those with migraine, had an increased risk of developing new-onset hypothyroidism [263, 264].

\section{Pathophysiological mechanisms}

Like other autoimmune disorders, hypothyroidism is a complex disease deriving from an interaction between a specific genetic background and environmental factors, therein leading to the exposure of thyroid autoantigens, which can induce the development of thyroid peroxidase and/or thyroglobulin autoantibodies. However, the mechanisms underlying the occurrence of headache in patients with hypothyroidism are unknown and merits investigation.

\section{Headache and immuno-mediated gastrointestinal disorders Epidemiological evidence}

Several studies reported a significant association between migraine and immuno-mediated gastrointestinal disorders especially celiac disease (CD) and inflammatory bowel disease (IBD) [265-267].

In a study involving 72 adult patients with biopsyproven $\mathrm{CD}$, screened for concomitant neurological disorders, $28 \%$ suffered from migraine often in association with other neurological symptoms [268]. Another recent research, involving 188 patients with proven $\mathrm{CD}$, found that there was a significantly higher prevalence of migraine in this group compared to controls $(\mathrm{OR}=3.79)$, particularly for females and for CD patients $<65$ years old. A greater proportion of patients with $\mathrm{CD}$ or gluten sensitivity (GS) (62 and 60\%, respectively) graded their migraine as severe, compared to patients with IBD (30\%) [269]. The link between migraine and CD suggested the benefit of a gluten-free diet for reducing migraine frequency in patients with both disorders. Accordingly, a preliminary study involving 90 migraineurs and 236 controls observed a CD prevalence of $4.4 \%$ in the migraine group vs $0.4 \%$ in controls. Overall, of the 4 patients having both migraine and $\mathrm{CD}$, for one, migraine disappeared at 6 months of a gluten-free diet, while the remaining three reported a significant reduction in intensity and frequency of headache [270]. A subsequent Italian study indicated that migraine-type headaches were more common in $\mathrm{CD}$ patients than in controls and partially improved with gluten-free die [271]. Results from other cohorts of $\mathrm{CD}$ patients demonstrated similar improvements in migraine-type headaches whenever dietary intervention was recommended [272, 273].

A recent systematic review and meta-analysis study, including 40 articles published between 1987 and 2017, reported a mean pooled prevalence of headache among 
patients with CD equal to $26 \%$ (95\% CI 19.5-33.9\%) in adult populations and $18.3 \%$ (95\% CI 10.4-30.2\%) in paediatric populations. The headaches most often had migraine-like characteristics. In children with idiopathic headache, the prevalence of CD was $2.4 \%$ (95\% CI $1.5-$ $3.7 \%)$, whereas data for adult populations on this were unavailable [274].

In patients suffering from both $\mathrm{CD}$ and migraine, it is sometimes possible to observe WM abnormalities and cerebral calcifications on MRI, as well as deranged regional cerebral blood flow on SPECT can be present in some cases [275-277].

Faced with a higher prevalence of migraine in $\mathrm{CD}$ patients compared to controls, current evidence does not clearly support the adoption of a routine search for IgA antitransglutamase antibodies within the diagnostic approach for patients with migraine [278, 279]. Only one cross-sectional study has reported a higher prevalence of positive tissue transglutaminase IgA (tTGA) antibodies in a group of paediatric migraine patients (5.5\%), compared to age- and sex-matched controls (0.6\%). However, in this study, most patients with positive antibodies had normal biopsies, thus challenging the veracity of $C D$ diagnosis and therein possibly highlighting the low diagnostic accuracy of only antibody testing [280].

As for celiac disease, the prevalence of migraine in IBD patients has been shown to be significantly higher than in the general population $(21.3 \%$ vs. $8.8 \%, p=$ 0.027), with attacks having a longer duration, but not a higher frequency, compared to controls [281]. Likewise, migraine prevalence resulted twofold higher in IBD patients compared to the general population in a subsequent investigation conducted by Moisset et al. In the same study, migraine was associated with younger age, female sex and higher depression scores. Although migraine impact was relevant for $30 \%$ of patients, specific acute treatments, however, were prescribed in only $22 \%$ of cases. The authors suggested that a systematic screening for migraine should be done by IBD specialists in daily practice to provide adequate treatment [282].

In a recent study involving 60,436 US adults aged $\geq 18$ years participating in the 2015 and 2016 National Health Interview Survey (NHIS), a higher prevalence of ageadjusted migraine or severe headache prevalence was reported among participants with IBD than those without IBD $(28.1 \%$ vs. $15.2 \%, \mathrm{p}<0.0001)$. This association [adjusted prevalence ratio $(95 \% \mathrm{CI})=1.59$ (1.35-1.86)] awas maintained after controlling for all other covariates [283].

\section{Pathophysiological mechanisms}

The pathophysiological mechanisms behind the association between migraine and immune-mediate gastrointestinal diseases (both $\mathrm{CD}$ and IBD) are not fully understood. One of the hypotheses which has been advanced to explain an association between $\mathrm{CD}$ and migraine sustains that there is a potential role of a generalized inflammatory response, rather than direct antibody-mediated mechanisms in the induction of migraine attacks via trigemino-vascular system activation [284]. Specifically, increased levels of pro-inflammatory cytokines such as IFN- $\gamma$ and TFN- $\alpha$ might be involved in the modulation and release of CGRP from trigeminal endings, which are in turn implicated in neurogenic inflammation; thus, possibly explaining the appearance and progression of migraine in CD patients [285, 286]. A similar mechanism has been advocated to explain the association between migraine and IBD. A lack of vitamins and/or macronutrients might contribute also to an association between migraine and CD [267].

In both inflammatory mediated disorders-IBD and $\mathrm{CD}-\mathrm{a}$ role for gastrointestinal microbiota has been suggested. Specifically, unbalanced gut flora might be associated with neurological diseases like migraine, that is dysbiosis and the increased intestinal permeability might contribute to enhanced pro-inflammatory response representing a potentially mediator of both disorders [267, 286, 287]. Furthermore, a dysfunction of the serotoninergic system might be implicated in the progression of IBD [288-290]. Since serotoninergic dysfunction is involved also in migraine [291, 292], it is possible that this neurotransmitter pathway might represent a link between these two disorders.

\section{Headache and allergic disorders Epidemiological evidence}

Several studies have investigated for an association between migraine and atopic diseases, both in adult and paediatric populations. In particular, a coexistence between asthma and migraine-type headaches has been described as well as a greater prevalence of hay fever, rhinitis, and dermatitis in migraineurs compared to healthy non-atopic controls [293-299]. Furthermore, children had a higher risk of asthma whenever their parents have had a history of migraine, suggesting that the two disorders might derive from a common denominator [300].

Asthma has also been indicated as a risk factor for new-onset chronic migraine [301-303]. In most of these studies, however, diagnosis of allergic disorders was not definitive and was solely based on the medical histories and allergic or respiratory symptoms, without spirometric confirmation. The most recent findings on this topic regard the presence of migraine in atopic children and vice versa. Specifically, in a study by Wang et al., the incidence of migraine was 3.2-fold higher in a cohort of children with atopic rhinitis, compared to a matched cohort of children without. The risk was greater for males, 
and for those aged $<6$ years, and highest within the first year after atopic rhinitis diagnosis [304]. A further study examining children with one or more previous allergic diseases (atopic dermatitis, allergic conjunctivitis, allergic rhinitis, and asthma) suggested that they had a greater subsequent risk of migraine compared to controls by the time they reached school age. Furthermore, with more allergic disease, a cumulative effect for the risk of migraine was observed [305]. In agreement with the mentioned results here, lower 'degrees of atopy' were associated with less frequent and disabling migraine headaches in younger patients, while higher degrees were associated with more frequent migraines.

Moreover, the immunotherapy administration seems to have induced a decreased prevalence, frequency, and disability of migraine headache in subjects with asthma $<45$ years of age [306]. A recent case-control study conducted across three European tertiary care hospitals revealed that children and adolescents with migraine were more likely to have persistent asthma and that persistent childhood asthma was associated with a higher frequency of migraine attacks. Interestingly, a history of anti-asthmatic or anti-allergic therapies was associated with a decreased risk of migraine, suggesting a potential role of these medications for the prevention of migraine occurrence [307]. Given this, physicians should be more aware of the risks of migraine in children with allergic diseases. In such cases, it would be reasonable to screen young migraineurs to exclude the presence of any atopic disorders particularly asthma, especially in those with a positive family history of asthma.

\section{Pathophysiological mechanisms}

Mechanisms underlying an association between migraine and atopic diseases remain a matter of debate. Common pathophysiologic pathways have been hypothesized. Specifically, platelet activating factor and vasoactive neuropeptides are thought to play a role in both asthma pathogenesis and the induction of migraine-type headache. Food sensitivities have also been suggested as possible triggers of migraine attacks. Indeed, not only respiratory allergens but also food allergens, such as red birch, hazel and olive trees, along with nettle and wheat, have been reported to lead to migraine attacks in some patients with positive allergy tests. In these patients, the frequency of migraine attacks was reported to be higher compared to negative ones [308]. Accordingly, skin prick tests and blood tests for IgE-specific food allergens have been suggested as useful tool for selecting patients with migraine who could likely benefit from an elimination diet [309]. However, in a cohort of 50 migraineurs tested by Pradalier et al., prick-tests and radioallergosorbent test resulted positive only for 4 and 6 patients (all of them atopic) respectively, thus suggesting a low possibility of an association between migraine and allergy to foods staples [310]. Although data are contrasting, IgG food sensitivity testing has also been proposed for patients with migraine who refer some foods as potential triggers for attacks [311]. This test might be useful in the view of providing tailored dietary recommendations for patients and in order to avoid, at least in some cases, the use of medications [310]. Moreover, an elimination diet based on IgG food sensitivity tests combined with probiotics has also been suggested to be beneficial for migraine patients with irritable bowel disease [312, 313].

\section{Conclusions}

This comprehensive review summarizes the findings to date regarding the association between headache and immunological/autoimmune disorders. Although studies are quite conflicting, over the last three decades, evidence has been moving towards a possible confirmation of the comorbidity of headache with almost all systemic immunological or autoimmune disorders or braindirected autoimmune diseases, with the exceptions being SLE and type $1 \mathrm{DM}$. In the former, there does not appear to be a strong association, while the latter appears to be even a protective factor for migraine. In Table 3, we summarize the strength of association between headache and immunological/autoimmune diseases.

As far as the mechanisms underlying these comorbidities is concerned, contrasting hypotheses have been advanced. For some immunological/autoimmune diseases, headache and particularly migraine, could be, at least in some cases, a direct consequence of the disease location at the level of CNS. For instance, in multiple sclerosis, demyelinating lesions in the brainstem might account

Table 3 Association between headache and immunomediated/ autoimmune diseases

\begin{tabular}{ll}
\hline Autoimmune disorders & $\begin{array}{l}\text { Association with } \\
\text { headaches }\end{array}$ \\
\hline Multiple sclerosis (MS) & $\uparrow$ \\
Vasculitis & $\uparrow$ \\
Systemic lupus erythematosus (SLE) & $=$ \\
Primary Sjögren's syndrome (pSS) & $\uparrow /=^{*}$ \\
Systemic scleroderma (SS) & $\uparrow^{* *}$ \\
Rheumathoid arthritis and other forms of arthritis & $\uparrow$ \\
Antiphospholipid syndrome (AP) & $\uparrow$ \\
Type 1 diabete mellitus (DM) & $\downarrow$ \\
Hypothyroidism & $\uparrow$ \\
Immunomediated gastrointestinal disorders & $\uparrow$ \\
Allergic disorders & $\uparrow$ \\
\hline
\end{tabular}

$\uparrow$ association; = no association; $\downarrow$ inverse association

* Some positive results, other negative

** A few studies are available on the association with headache 
for the occurrence of headache, especially of cluster-like headache or trigeminal neuralgia. Alternatively, the migraine phenotype might be a consequence of general inflammatory mechanisms involving meningeal vessels and activating trigeminal terminals, especially in individuals with a previous history of migraine. Furthermore, in patients with chronic autoimmune disorders, headache, especially with tension-type features, could be reactive to the psychological burden of the diagnosis. Finally, as with most headaches, several stressors, especially infections and emotional stress, can trigger autoimmune disease exacerbation.

Immunological/autoimmune disorders and headache tend to worsen each other. Indeed, on one hand, several immunological/autoimmune diseases during active phases can exacerbate headache; on the other hand, the presence of headache in patients with immunological/ autoimmune disorders worsens their quality of life. Therefore, a tailored treatment plan based on the most appropriate choice of acute and prophylactic therapies is needed in patients with both headache and immunological/autoimmune diseases. In this view, stricter cooperation between headache specialists and rheumatologists needs to be achieved in order to improve patients' quality of life.

\section{Abbreviations}

aCL: Anticardiolipin; aPL: Antiphospholipid; APS: Antiphospholipid syndrome; b2GPI: Anti-b-2-glycoprotein I; CGRP: Calcitonin gene-related peptide; CD: Celiac disease; CH: Cluster headache; CIS: Clinically isolated syndrome; CNS: Central nervous system; Cr: Creatine; CSD: Cortical spreading depression; CSF: Cerebrospinal fluid; DM1: Type 1 diabetes mellitus; DM2: Type 2 diabetes mellitus; DSA: Digital subtraction angiography; EDSS: Expanded Disability Status Scale; FMF: Familial Mediterranean fever; GCA: Giant cell arteritis; HLA: Human leukocyte antigens; IBD: Inflammatory bowel disease; ICHD: International Classification of Headache Disorders; IL: Interleukin; JIA: Juvenile idiopathic arthritis; LA: Lupus anticoagulant; LS: Localized scleroderma; MA: Migraine with aura; MCP: Monocyte chemoattractant protein; MRI: Magnetic resonance imaging; MRS: Magnetic resonance spectroscopy; MS: Multiple sclerosis; MwA: Migraine without aura; NAA: N-Acetylaspartate; NAPS: Neurological antiphospholipid syndrome; NK: Natural killer; NPSLE: Neuropsychiatric Systemic lupus erythematosus; PACNS: Primary angiitis of the central nervous system; PAG: Periaqueductal grey; PAN: Polyarteritis nodosa; PAPS: Primary antiphospholipid syndrome; PNS: Peripheral nervous system; pSS: Primary Sjögren's syndrome; PT: Prothrombin; RA: Rheumatoid arthritis; RAPS: Rheumatologic antiphospholipid syndrome; RCVS: Reversible cerebral vasoconstriction syndrome; RIS: Radiologically isolated syndrome; RRMS: Relapsing/remitting MS; SAPS: Secondary antiphospholipid syndrome; SLE: Systemic lupus erythematosus; SLEDAl: SLE Disease Activity Index; SLICC: Systemic Lupus International Collaborating Clinics; SPECT: Single-photon emission computed tomography; SS: Sjögren's syndrome; SSc: Systemic scleroderma; sSS: Secondary Sjögren's syndrome; TAKA: Takayasu's arteritis; TG: Trigeminal ganglion; TN: Trigeminal neuralgia; TNC: Trigeminal nucleus caudalis; TNF: Tumour necrosis factor; TN-MS: Trigeminal neuralgia secondary to multiple sclerosis; TPO: Thyroid peroxidase; tTGA: Tissue transglutaminase IgA; TTH: Tension-type headache

\section{Acknowledgements}

Not applicable

\section{Authors' contributions}

L.B. and P.S. wrote the manuscript. All remaining authors researched data for the article, made substantial contributions to the discussion of the content and reviewed and/or edited the manuscript before submission. The authors read and approved the final manuscript.

\section{Availability of data and materials}

The authors searched data for this review article from the online archives Pubmed and Embase.

\section{Declarations}

Ethics approval and consent to participate

Not applicable

\section{Consent for publication}

Not applicable

\section{Competing interests}

The authors declare that they do not have any competing interest.

\section{Author details}

${ }^{1}$ Istituto Nazionale di Riposo e Cura dell'Anziano a carattere scientifico, IRCSSINRCA, Ancona, Italy. ${ }^{2}$ Section of Neurology, Department of Medicine and Surgery, University of Perugia, Perugia, Italy. ${ }^{3}$ Headache Center, UOC Neurologia-Stroke Unit, Emergency Department, Ospedale S. Eugenio, Rome, Italy. ${ }^{4}$ Department of Neuroscience, Università Cattolica Sacro Cuore, Rome, Italy.

Received: 26 April 2021 Accepted: 4 August 2021

Published online: 08 November 2021

\section{References}

1. Ngo ST, Steyn FJ, McCombe PA. Gender differences in autoimmune disease Front Neuroendocrinol. 2014;35(3):347-69 https://doi.org/10.1016/j.yfrne.2 014.04.004.

2. Pennell LM, Galligan CL, Fish EN. Sex affects immunity. J Autoimmun. 2012; 38(2-3):J282-91 https://doi.org/10.1016/j.jaut.2011.11.013.

3. Stovner LJ, Zwart JA, Hagen K, Terwindt GM, Pascual J. Epidemiology of headache in Europe. Eur J Neurol. 2006;13(4):333-45 https://doi.org/10.1111/ j.1468-1331.2006.01184.x.

4. Wang L, Wang FS, Gershwin ME. Human autoimmune diseases: a comprehensive update. J Intern Med. 2015;278(4):369-95 https://doi.org/1 $0.1111 /$ joim.12395

5. Ji RR, Nackley A, Huh Y, Terrando N, Maixner W. Neuroinflammation and Central Sensitization in Chronic and Widespread Pain. Anesthesiology. 2018; 129(2):343-66 https://doi.org/10.1097/ALN.0000000000002130.

6. Cavestro C, Ferrero M, Mandrino S, Di Tavi M, Rota E. Novelty in inflammation and immunomodulation in migraine. Curr Pharm Des. 2019: 25(27):2919-36 https://doi.org/10.2174/1381612825666190709204107.

7. Jarrahi A, Braun M, Ahluwalia M, Gupta RV, Wilson M, Munie S, et al. Revisiting Traumatic Brain Injury: From Molecular Mechanisms to Therapeutic Interventions. Biomedicines. 2020;8(10):389 https://doi.org/10.33 90/biomedicines8100389.

8. Hori H, Kim Y. Inflammation and post-traumatic stress disorder. Psychiatry Clin Neurosci. 2019;73(4):143-53 https://doi.org/10.1111/pcn.12820.

9. Levy D, Labastida-Ramirez A, MaassenVanDenBrink A. Current understanding of meningeal and cerebral vascular function underlying migraine headache. Cephalalgia. 2019;39(13):1606-22 https://doi.org/10.1177/0333102418771350.

10. Levy D. Endogenous mechanisms underlying the activation and sensitization of meningeal nociceptors: the role of immuno-vascular interactions and cortical spreading depression. Curr Pain Headache Rep. 2012;16(3):270-7 https://doi.org/10.1007/s11916-012-0255-1.

11. Kulka M, Sheen CH, Tancowny BP, Grammer LC, Schleimer RP. Neuropeptides activate human mast cell degranulation and chemokine production. Immunology. 2008;123(3):398-410 https://doi.org/10.1111/j.13 65-2567.2007.02705.x.

12. Jansen-Olesen I, Hougaard PS. PACAP and its receptors in cranial arteries and mast cells. J Headache Pain. 2018;19(1):16 https://doi.org/10.1186/s101 94-017-0822-2. 
13. Malick A, Burstein R. Peripheral and central sensitization during migraine. Funct Neurol. 2000;15:28-35.

14. Edvinsson L, Haanes KA, Warfvinge K. Does inflammation have a role in migraine? Nat Rev Neurol. 2019;15(8):483-90 https://doi.org/10.1038/s41582019-0216-y.

15. Kristiansen KA, Edvinsson L. Neurogenic inflammation: a study of rat trigeminal ganglion. J Headache Pain. 2010;11(6):485-95 https://doi.org/10.1 007/s10194-010-0260-x

16. Afroz S, Arakaki R, Iwasa T, Oshima M, Hosoki M, Inoue M, et al. CGRP induces differential regulation of cytokines from satellite glial cells in trigeminal ganglia and orofacial nociception. Int J Mol Sci. 2019;20(3):711 https://doi.org/10.3390/ijms20030711.

17. Jing F, Zhang Y, Long T, He W, Qin G, Zhang D, et al. P2Y12 receptor mediates microglial activation via RhoA/ROCK pathway in the trigeminal nucleus caudalis in a mouse model of chronic migraine. J Neuroinflammation. 2019;16(1):217 https://doi.org/10.1186/s12974-019-1603-4

18. He W, Long T, Pan Q, Zhang S, Zhang Y, Zhang D, et al. Microglial NLRP3 inflammasome activation mediates IL-1 $\beta$ release and contributes to central sensitization in a recurrent nitroglycerin-induced migraine model. J Neuroinflammation. 2019;16(1):78 https://doi.org/10.1186/s12974-019-1459-7.

19. Long T, Pan Q, Zhang S, Zhang Y, Zhang D, Qin G, et al. Microglial NLRP3 inflammasome activation mediates $I L-1 \beta$ release and contributes to central sensitization in a recurrent nitroglycerin-induced migraine model. J Neuroinflammation. 2019;16(1):78.

20. Afroz S, Arakaki R, Iwasa T, Waskitho A, Oshima M, Matsuka Y. Role of CGRP in neuroimmune interaction via NF-kB signaling genes in glial cells of trigeminal ganglia. Int J Mol Sci. 2020;21(17):6005 https://doi.org/10.3390/ ijms21176005

21. Jander S, Schroeter M, Peters O, Witte OW, Stoll G. Cortical spreading depression induces proinflammatory cytokine gene expression in the rat brain. J Cereb Blood Flow Metab. 2001;21(3):218-25 https://doi.org/10.1097/ 00004647-200103000-00005.

22. Kunkler PE, Hulse RE, Kraig RP. Multiplexed cytokine protein expression profiles from spreading depression in hippocampal organotypic cultures. J Cereb Blood Flow Metab. 2004;24(8):829-39 https://doi.org/10.1097/01. WCB.0000126566.34753.30.

23. Thompson CS, Hakim AM. Cortical spreading depression modifies components of the inflammatory cascade. Mol Neurobiol. 2005;32(1):51-7 https://doi.org/10.1385/MN:32:1:051.

24. Urbach A, Bruehl C, Witte OW. Microarray-based long-term detection of genes differentially expressed after cortical spreading depression. Eur J Neurosci. 2006;24(3):841-56 https://doi.org/10.1111/j.1460-9568.2006.04862.x.

25. Ghaemi A, Alizadeh L, Babaei S, Jafarian M, Khaleghi Ghadiri M, Meuth SG, et al. Astrocyte-mediated inflammation in cortical spreading depression. Cephalalgia. 2018;38(4):626-38 https://doi.org/10.1177/0333102417702132.

26. Albrecht DS, Mainero C, Ichijo E, Ward N, Granziera C, Zürcher NR, et al. Imaging of neuroinflammation in migraine with aura: $\mathrm{A}\left[{ }^{11} \mathrm{C}\right] \mathrm{PBR} 28 \mathrm{PET} / \mathrm{MRI}$ study. Neurology. 2019;92(17):e2038-50 https://doi.org/10.1212/WNL. 0000000000007371.

27. Rainero I, Fasano E, Rubino E, Rivoiro C, Valfrè W, Gallone S, et al. Association between migraine and HLA-DRB1 gene polymorphisms. $J$ Headache Pain. 2005;6(4):185-7 https://doi.org/10.1007/s10194-005-0180-3.

28. Yilmaz IA, Ozge A, Erdal ME, Edgünlü TG, Cakmak SE, Yalin OO. Cytokine polymorphism in patients with migraine: some suggestive clues of migraine and inflammation. Pain Med. 2010;11(4):492-7 https://doi.org/10.1111/j.152 6-4637.2009.00791.x

29. Uzar E, Evliyaoglu O, Yucel Y, Ugur Cevik M, Acar A, Guzel I, et al. Serum cytokine and pro-brain natriuretic peptide (BNP) levels in patients with migraine. Eur Rev Med Pharmacol Sci. 2011;15(10):1111-6.

30. Kemper RH, Meijler WJ, Korf J, Ter Horst GJ. Migraine and function of the immune system: a meta-analysis of clinical literature published between 1966 and 1999. Cephalalgia. 2001;21(5):549-57 https://doi.org/10.1046/j.14 68-2982.2001.00196.x.

31. Duarte $H$, Teixeira AL, Rocha NP, Domingues RB. Increased interictal serum levels of CXCL8/IL-8 and CCL3/MIP-1a in migraine. Neurol Sci. 2015;36(2): 203-8 https://doi.org/10.1007/s10072-014-1931-1.

32. Oliveira AB, Bachi ALL, Ribeiro RT, Mello MT, Tufik S, Peres MFP. Unbalanced plasma TNF- $a$ and IL-12/IL-10 profile in women with migraine is associated with psychological and physiological outcomes. J Neuroimmunol. 2017;313: 138-44 https://doi.org/10.1016/j.jneuroim.2017.09.008.
33. Perini F, D'Andrea G, Galloni E, Pignatelli F, Billo G, Alba S, et al. Plasma cytokine levels in migraineurs and controls. Headache. 2005;45(7):926-31 https://doi.org/10.1111/j.1526-4610.2005.05135.x.

34. Fidan I, Yüksel S, Ymir T, Irkeç C, Aksakal FN. The importance of cytokines, chemokines and nitric oxide in pathophysiology of migraine. J Neuroimmunol. 2006;171(1-2):184-8 https://doi.org/10.1016/j.jneuroim.2 005.10.005.

35. Munno I, Marinaro M, Bassi A, Cassiano MA, Causarano V, Centonze V. Immunological aspects in migraine: increase of IL-10 plasma levels during attack. Headache. 2001;41(8):764-7 https://doi.org/10.1046/j.1526-4610.2001. 01140.x.

36. Beebe AM, Cua DJ, de Waal Malefyt R. The role of interleukin-10 in autoimmune disease: systemic lupus erythematosus (SLE) and multiple sclerosis (MS). Cytokine Growth Factor Rev. 2002;13(4-5):403-12 https://doi. org/10.1016/S1359-6101(02)00025-4.

37. Groux H, Cottrez F. The complex role of interleukin-10 in autoimmunity. J Autoimmun. 2003;20(4):281-5 https://doi.org/10.1016/S0896-8411(03)00044-1.

38. Mosnaim AD, Kulaga H, Adams AJ, Wolf ME, Puente J, Freitag F, et al. Flow cytometric analysis of lymphocyte subsets in migraine patients during and outside of an acute headache attack. Cephalalgia. 1998;18(4):197-201 https://doi.org/10.1046/j.1468-2982.1998.1804197.x.

39. Covas Ml, Esquerda A, García-Rico A, Mahy N. Peripheral blood Tlymphocyte subsets in autoimmune thyroid disease. J Investig Allergol Clin Immunol. 1992;2(3):131-5.

40. Deckert M, Sanchez-Ruiz M, Brunn A, Schluter D. Role of CD8 T-cellmediated autoimmune diseases of the central nervous system. Crit Rev Immunol. 2010;30(4):311-26 https://doi.org/10.1615/CritRevlmmunol.v30.14.10.

41. Pender MP, Csurhes PA, Pfluger CM, Burrows SR. CD8+ T cells far predominate over CD4+ T cells in healthy immune response to Epstein-Barr virus infected lymphoblastoid cell lines. Blood. 2012;120(25):5085-7 https:// doi.org/10.1182/blood-2012-06-437285.

42. Arumugam $M$, Parthasarathy $V$. Reduction of $C D 4(+) C D 25(+)$ regulatory T-cells in migraine: is migraine an autoimmune disorder? J Neuroimmunol. 2016;290:54-9 https://doi.org/10.1016/j.jneuroim.2015.11.015.

43. Martelletti $P$, Giacovazzo M. Putative neuroimmunological mechanisms in cluster headache. An integrated hypothesis. Headache. 1996;36(5):312-5 https://doi.org/10.1046/j.1526-4610.1996.3605312.x.

44. Remahl IN, Waldenlind $\mathrm{E}$, Bratt J, Ekbom K. Cluster headache is not associated with signs of a systemic inflammation. Headache. 2000;40(4):27682 https://doi.org/10.1046/j.1526-4610.2000.00041.x.

45. Domingues RB, Duarte $H$, Rocha NP, Teixeira AL. Increased serum levels of interleukin-8 in patients with tension-type headache. Cephalalgia. 2015; 35(9):801-6 https://doi.org/10.1177/0333102414559734.

46. Koçer A, Koçer E, Memişoğullari R, Domaç FM, Yüksel H. Interleukin-6 levels in tension headache patients. Clin J Pain. 2010;26(8):690-3 https://doi.org/1 0.1097/AJP.0b013e3181e8d9b6.

47. Della Vedova C, Cathcart S, Dohnalek A, Lee V, Hutchinson MR, Immink MA, et al. Peripheral interleukin-1ß levels are elevated in chronic tension-type headache patients. Pain Res Manag. 2013;18(6):301-6 https://doi.org/10.11 55/2013/796161.

48. Bø SH, Davidsen EM, Gulbrandsen P, Dietrichs E, Bovim G, Stovner LJ, et al. Cerebrospinal fluid cytokine levels in migraine, tension-type headache and cervicogenic headache. Cephalalgia. 2009;29(3):365-72 https://doi.org/1 0.1111/j.1468-2982.2008.01727.x.

49. Binshtok AM, Wang H, Zimmermann K, Amaya F, Vardeh D, Shi L, et al. Nociceptors are interleukin-1beta sensors. J Neurosci. 2008;28(52):14062-73 https://doi.org/10.1523/JNEUROSCI.3795-08.2008.

50. Garg N, Smith TW. An update on immunopathogenesis, diagnosis, and treatment of multiple sclerosis. Brain Behav. 2015;5:e00362.

51. Lemus HN, Warrington AE, Rodriguez M. Multiple Sclerosis: Mechanisms of Disease and Strategies for Myelin and Axonal Repair. Neurol Clin. 2018;36(1): 1-11 https://doi.org/10.1016/j.ncl.2017.08.002.

52. Tabby DD, Majeed MH, Youngman B, Wilcox J. Headache in multiple sclerosis: features and implications for disease management. Int J MS Care. 2013;15:73-80.

53. Villani V, De Giglio L, Sette G, Pozzilli C, Salvetti M, Prosperini L. Determinants of the severity of comorbid migraine in multiple sclerosis. Neurol Sci. 2012;33(6):1345-53 https://doi.org/10.1007/s10072-012-1119-5.

54. Poser CM, Presthus J, Hörsdal O. Clinical characteristics of autopsy-proved multiple sclerosis. Neurology. 1966;16:791-6. 
55. Watkins SM, Espir M. Migraine and multiple sclerosis. J Neurol Neurosurg Psychiatry. 1969;32(1):35-7 https://doi.org/10.1136/jnnp.32.1.35.

56. Kruit MC, van Buchem MA, Launer $L$, Terwindt GM, Ferrari MD. Migraine is associated with an increased risk of deep white matter lesions, subclinical posterior circulation infarcts and brain iron accumulation: the populationbased MRI CAMERA study. Cephalalgia. 2010;30(2):129-36 https://doi.org/1 0.1111/j.1468-2982.2009.01904.x

57. Freedman MS, Gray TA. Vascular headache: a presenting symptom of multiple sclerosis. Can J Neurol Sci. 1989;16(1):63-6 https://doi.org/10.1017/ S0317167100028523.

58. Abb L, Schaltenbrand G. Statistische Untersuchungen zum Problem der Multiplen Sklerose. II. Das Krankheitsbild der Multiplen Sklerose [Statistical study of the problem of multiple sclerosis. II. The clinical aspects of the disease]. Dtsch Z Nervenheilkd. 1956;174(3):201-18.

59. Martinelli Boneschi F, Colombo B, Annovazzi P, Martinelli V, Bernasconi L, Solaro $C$, et al. Lifetime and actual prevalence of pain and headache in multiple sclerosis. Mult Scler. 2008;14(4):514-21 https://doi.org/10.1177/13 52458507085551.

60. Clifford DB, Trotter JL. Pain in multiple sclerosis. Arch Neurol. 1984;41(12): 1270-2 https://doi.org/10.1001/archneur.1984.04050230052017.

61. D'Amico D, La Mantia L, Rigamonti A, Usai S, Mascoli N, Milanese C, et al. Prevalence of primary headaches in people with multiple sclerosis. Cephalalgia. 2004;24(11):980-4 https://doi.org/10.1111/j.1468-2982.2004.00790.x.

62. Kister I, Caminero AB, Monteith TS, Soliman A, Bacon TE, Bacon JH, et al. Migraine is comorbid with multiple sclerosis and associated with a more symptomatic MS course. J Headache Pain. 2010;11(5):417-25 https://doi. org/10.1007/s10194-010-0237-9.

63. Möhrke J, Kropp P, Zettl UK. Headaches in multiple sclerosis patients might imply an inflammatorial process. PLoS One. 2013;8(8):e69570 https://doi. org/10.1371/journal.pone.0069570.

64. Nicoletti A, Patti F, Lo Fermo S, Liberto A, Castiglione A, Laisa P, et al. Headache and multiple sclerosis: a population-based case-control study in Catania. Sicily. Cephalalgia. 2008;28(11):1163-9 https://doi.org/10.1111/j.14 68-2982.2008.01662.x.

65. Putzki N, Pfriem A, Limmroth V, Yaldizli O, Tettenborn B, Diener HC, et al. Prevalence of migraine, tension-type headache and trigeminal neuralgia in multiple sclerosis. Eur J Neurol. 2009;16(2):262-7 https://doi.org/10.1111/j.14 68-1331.2008.02406.x.

66. Vacca G, Marano E, Brescia Morra V, Lanzillo R, De Vito M, Parente E, et al. Multiple sclerosis and headache co-morbidity. A case-control study. Neurol Sci. 2007;28(3):133-5 https://doi.org/10.1007/s10072-007-0805-1.

67. Villani V, Prosperini L, Ciuffoli A, Pizzolato R, Salvetti M, Pozzilli C, Sette G. Primary headache and multiple sclerosis: preliminary results of a prospective study. Neurol Sci. 2008;29(Suppl 1):S146-8 https://doi.org/10.1007/s10072008-0908-3

68. Beckmann $Y$, Türe S. Headache characteristics in multiple sclerosis. Mult Scler Relat Disord. 2019;27:112-6 https://doi.org/10.1016/j.msard.2018.09.022.

69. Fragoso YD, Adoni T, Alves-Leon SV, Apostolos-Pereira SL, Carneiro MAD Chikota EM, et al. Migraine in 746 patients with multiple sclerosis. Arq Neuropsiquiatr. 2019;77(9):617-21 https://doi.org/10.1590/0004-282×20190100.

70. Sahai-Srivastava S, Wang SL, Ugurlu C, Amezcua L. Headaches in multiple sclerosis: Cross-sectional study of a multiethnic population. Clin Neurol Neurosurg. 2016;143:71-5 https://doi.org/10.1016/j.clineuro.2016.01.017.

71. Gustavsen MW, Celius EG, Winsvold BS, Moen SM, Nygaard GO, BergHansen $\mathrm{P}$, et al. Migraine and frequent tension-type headache are not associated with multiple sclerosis in a Norwegian case-control study. Mult Scler J Exp Transl Clin. 2016;2:2055217316682976.

72. Ergün U, Ozer G, Sekercan S, Artan E, Kudiaki C, Uçler S, et al. Headaches in the different phases of relapsing-remitting multiple sclerosis: a tendency for stabbing headaches during relapses. Neurologist. 2009;15(4):212-6 https:// doi.org/10.1097/NRL.0b013e3181906fc9.

73. Simpson RJ, McLean G, Guthrie B, Mair F, Mercer SW. Physical and mental health comorbidity is common in people with multiple sclerosis: nationally representative cross-sectional population database analysis. BMC Neurol. 2014;14(1):128 https://doi.org/10.1186/1471-2377-14-128.

74. JChen J, Taylor B, Winzenberg T, Palmer AJ, Kirk-Brown A, van Dijk P, et al. Comorbidities are prevalent and detrimental for employment outcomes in people of working age with multiple sclerosis. Mult Scler. 2020;26:1550-9.

75. Zorzon M, Zivadinov R, Nasuelli D, Dolfini P, Bosco A, Bratina A, et al. Risk factors of multiple sclerosis: a case-control study. Neurol Sci. 2003;24(4):2427 https://doi.org/10.1007/s10072-003-0147-6.
76. Kister I, Munger KL, Herbert J, Ascherio A. Increased risk of multiple sclerosis among women with migraine in the Nurses' Health Study II. Mult Scler. 2012;18(1):90-7 https://doi.org/10.1177/1352458511416487.

77. Pakpoor J, Handel AE, Giovannoni G, Dobson R, Ramagopalan SV. Metaanalysis of the relationship between multiple sclerosis and migraine. PLoS One. 2012;7(9):e45295 https://doi.org/10.1371/journal.pone.0045295.

78. Mirmosayyeb O, Barzegar M, Nehzat N, Shaygannejad V, Sahraian MA, Ghajarzadeh $\mathrm{M}$. The prevalence of migraine in multiple sclerosis (MS): A systematic review and meta-analysis. J Clin Neurosci. 2020;79:33-8 https:// doi.org/10.1016/j.jocn.2020.06.021.

79. Gebhardt M, Kropp P, Jürgens TP, Hoffmann F, Zettl UK. Headache in the first manifestation of multiple sclerosis - prospective, multicenter study. Brain Behav. 2017;7(12):e00852 https://doi.org/10.1002/brb3.852.

80. Granberg T, Martola J, Kristoffersen-Wiberg M, Aspelin P, Fredrikson S. Radiologically isolated syndrome--incidental magnetic resonance imaging findings suggestive of multiple sclerosis, a systematic review. Mult Scler. 2013;19(3):271-80 https://doi.org/10.1177/1352458512451943.

81. Howell OW, Reeves CA, Nicholas R, Carassiti D, Radotra B, Gentleman SM, et al. Meningeal inflammation is widespread and linked to cortical pathology in multiple sclerosis. Brain. 2011;134(Pt 9):2755-71 https://doi.org/10.1093/ brain/awr182.

82. Magliozzi R, Howell O, Vora A, Serafini B, Nicholas R, Puopolo M, et al. Meningeal B-cell follicles in secondary progressive multiple sclerosis associate with early onset of disease and severe cortical pathology. Brain. 2007;130(Pt 4):1089-104 https://doi.org/10.1093/brain/awm038.

83. Elliott DG. Migraine in multiple sclerosis. Int Rev Neurobiol. 2007;79:281-302 https://doi.org/10.1016/S0074-7742(07)79012-8.

84. Hamamcı M, Göcmen AY, Say B, Alpua M, Badem ND, Ergün U, et al. Why do multiple sclerosis and migraine coexist? Mult Scler Relat Disord. 2020;40: 101946 https://doi.org/10.1016/j.msard.2020.101946.

85. Gee JR, Chang J, Dublin AB, Vijayan N. The association of brainstem lesions with migraine-like headache: an imaging study of multiple sclerosis. Headache. 2005;45(6):670-7 https://doi.org/10.1111/j.1526-4610.2005.05136.x.

86. Arrese I, Lagares A, Alday R, Ramos A, Rivas JJ, Lobato RD. Typical trigeminal neuralgia associated with brainstem white matter lesions on MRI in patients without criteria of multiple sclerosis. Acta Neurochir. 2008;150:1157-61.

87. Tohyama S, Hung PS, Cheng JC, Zhang JY, Halawani A, Mikulis DJ, et al. Trigeminal neuralgia associated with a solitary pontine lesion: clinical and neuroimaging definition of a new syndrome. Pain. 2020;161(5):916-25 https://doi.org/10.1097/j.pain.0000000000001777.

88. Noory N, Smilkov EA, Frederiksen JL, Heinskou TB, Andersen ASS, Bendtsen $L$, et al. Neurovascular contact plays no role in trigeminal neuralgia secondary to multiple sclerosis. Cephalalgia. 2021;41(5):593-603 https://doi. org/10.1177/0333102420974356.

89. Mijajlović MD, Aleksić VM, Covičković Šternić NM. Cluster headache as a first manifestation of multiple sclerosis: case report and literature review. Neuropsychiatr Dis Treat. 2014;10:2269-74 https://doi.org/10.2147/NDT.S73491.

90. Nikfar S, Rahimi R, Abdollahi M. A meta-analysis of the efficacy and tolerability of interferon- $\beta$ in multiple sclerosis, overall and by drug and disease type. Clin Ther. 2010;32(11):1871-88 https://doi.org/10.1016/j. clinthera.2010.10.006.

91. Patti F, Nicoletti A, Pappalardo A, Castiglione A, Lo Fermo S, Messina S, et al. Frequency and severity of headache is worsened by Interferon- $\beta$ therapy in patients with multiple sclerosis. Acta Neurol Scand. 2012;125(2):91-5 https:// doi.org/10.1111/j.1600-0404.2011.01532.x.

92. De Jong HJI, Kingwell E, Shirani A, Cohen Tervaert JW, Hupperts R, Zhao Y, et al. Evaluating the safety of $\beta$-interferons in MS: a series of nested casecontrol studies. Neurology. 2017:88:2310-20.

93. Caon C, Namey M, Meyer C, Mayer L, Oyuela P, Margolin DH, et al. Prevention and management of infusion-associated reactions in the Comparison of Alemtuzumab and Rebif $\left({ }^{\oplus}\right)$ Efficacy in Multiple Sclerosis (CARE-MS) program. Int J MS Care. 2015;174:191-8.

94. Fragoso YD. Multiple sclerosis treatment with fingolimod: profile of noncardiologic adverse events. Acta Neurol Belg. 2017;117(4):821-7 https://doi. org/10.1007/s13760-017-0794-7.

95. Confavreux C, O'Connor P, Comi G, Freedman MS, Miller AE, Olsson TP, et al Oral teriflunomide for patients with relapsing multiple sclerosis (TOWER): a randomised, double-blind, placebo-controlled, phase 3 trial. Lancet Neurol. 2014;13(3):247-56 https://doi.org/10.1016/S1474-4422(13)70308-9.

96. Villani V, Prosperini L, De Giglio L, Pozzilli C, Salvetti M, Sette G. The impact of interferon beta andnatalizumab on comorbid migraine in multiple 
sclerosis. Headache. 2012;52(7):1130-5. https://doi.org/10.1111/j.1526-4610.2 012.02146.x Epub 2012 Apr 5.

97. Havrdova EE, Hutchinson M, Kurukulasuriya NC, Raghupathi K, Sweetser MT, Dawson KT, et al. Oral BG-12 (dimethyl fumarate) for relapsing-remitting multiple sclerosis: a review of DEFINE and CONFIRM. Evaluation of: Gold R, Kappos L, Arnold D, et al. Placebo-controlled phase 3 study of oral BG-12 for relapsing multiple sclerosis. N Engl J Med. 2012;367:1098-107 https://doi. org/10.1056/NEJMoa1114287.

98. Casili G, Lanza M, Filippone A, Campolo M, Paterniti I, Cuzzocrea S, et al. Dimethyl fumarate alleviates the nitroglycerin (NTG)-induced migraine in mice. J Neuroinflammation. 2020;17(1):59 https://doi.org/10.1186/s12974-02 0-01736-1.

99. Husain F, Pardo G, Rabadi M. Headache and Its Management in Patients With Multiple Sclerosis. Curr Treat Options Neurol. 2018;24(20):10.

100. Schoenen J, Manise M, Nonis R, Gérard P, Timmermans G. Monoclonal antibodies blocking CGRP transmission: an update on their added value in migraine prevention. Rev Neurol (Paris). 2020;176(10):788-803 https://doi. org/10.1016/.j.neurol.2020.04.027.

101. Caronna E, Starling AJ. Update on calcitonin gene-related peptide antagonism in the treatment of migraine. Neurol Clin. 2021;39(1):1-19 https://doi.org/10.1016/j.ncl.2020.09.001.

102. Ray JC, Kapoor M, Stark RJ, Wang SJ, Bendtsen L, Matharu M, Hutton EJ. Calcitonin gene related peptide in migraine: current therapeutics, future implications and potential off-target effects. J Neurol Neurosurg Psychiatry 2021:jnnp-2020-324674; https://doi.org/10.1136/jnnp-2020-324674.

103. Holzmann B. Antiinflammatory activities of CGRP modulating innate immune responses in health and disease. Curr Protein Pept Sci. 2013;14(4): 268-74 https://doi.org/10.2174/13892037113149990046.

104. Assas BM. Anti-migraine agents from an immunological point of view. J Transl Med. 2021;19(1):23 https://doi.org/10.1186/s12967-020-02681-6.

105. Lopez JI, Holdridge A, Chalela J. Headache and vasculitis. Curr Pain Headache Rep. 2013;17(3):320 https://doi.org/10.1007/s11916-012-0320-9.

106. Kidd $D$. The prevalence of headache in Behçet's syndrome. Rheumatology (Oxford). 2006;45(5):621-3 https://doi.org/10.1093/rheumatology/kei255.

107. Ness T, Bley TA, Schmidt WA, Lamprecht P. The diagnosis and treatment of giant cell arteritis. Dtsch Arztebl Int. 2013;110:376-85.

108. Vaith P, Warnatz K. Internistische und serologische Befunde der Riesenzellarteriitis [clinical and serological findings of giant-cell arteritis]. Z Rheumatol. 2009;68(2):124-31 https://doi.org/10.1007/s00393-008-0377-3.

109. Schmidt J, Warrington KJ. Polymyalgia rheumatica and giant cell arteritis in older patients: diagnosis and pharmacological management. Drugs Aging. 2011;28(8):651-66 https://doi.org/10.2165/11592500-000000000-00000.

110. Ly KH, Régent A, Tamby MC, Mouthon L. Pathogenesis of giant cell arteritis: More than just an inflammatory condition? Autoimmun Rev. 2010;9(10):63545 https://doi.org/10.1016/j.autrev.2010.05.002.

111. Weyand CM, Hicok KC, Hunder GG, Goronzy JJ. Tissue cytokine patterns in patients with polymyalgia rheumatica and giant cell arteritis. Ann Intern Med. 1994;121(7):484-91 https://doi.org/10.7326/0003-4819-121-7-199410010-00003.

112. Cid MC, Cebrián M, Font C, Coll-Vinent B, Hernández-Rodríguez J, Esparza J, et al. Cell adhesion molecules in the development of inflammatory infiltrates in giant cell arteritis: inflammation-induced angiogenesis as the preferential site of leukocyte-endothelial cell interactions. Arthritis Rheum. 2000;43(1):184-94 https://doi.org/10.1002/1529-0131(200001)43:1<184::AID-A NR23>3.0.CO;2-N.

113. Ciccia F, Rizzo A, Ferrante A, Guggino G, Croci S, Cavazza A, et al. New insights into the pathogenesis of giant cell arteritis. Autoimmun Rev. 2017; 16(7):675-83 https://doi.org/10.1016/j.autrev.2017.05.004.

114. Salvarani C, Brown RD Jr, Calamia KT, Christianson TJ, Weigand SD, Miller DV, et al. Primary central nervous system vasculitis: analysis of 101 patients. Ann Neurol. 2007;62(5):442-51.1 https://doi.org/10.1002/ana.21226

115. MKraemer M, Berlit P. Primary central nervous system vasculitis: clinical experiences with 21 new European cases. Rheumatol Int. 2011;31(4):463-72 https://doi.org/10.1007/s00296-009-1312-x.

116. Salvarani C, Brown RD Jr, Calamia KT, Christianson TJ, Huston J 3rd, Meschia $\mathrm{JF}$, et al. Rapidly progressive primary central nervous system vasculitis. Rheumatology (Oxford). 2011;50:349-58.

117. John S, Hajj-Ali RA. CNS vasculitis. Semin Neurol. 2014;34(04):405-12 https:// doi.org/10.1055/s-0034-1390389.

118. Salvarani C, Brown RD Jr, Hunder GG. Adult primary central nervous system vasculitis. Lancet. 2012;380(9843):767-77 https://doi.org/10.1016/50140-673 6(12)60069-5.
119. Hajj-Ali RA, Singhal AB, Benseler S, Molloy E, Calabrese LH. Primary angiitis of the CNS. Lancet Neurol. 2011;10(6):561-72 https://doi.org/10.1016/S14 74-4422(11)70081-3.

120. Néel A, Auffray-Calvier E, Guillon B, Fontenoy AM, Loussouarn D, Pagnoux C, et al. Challenging the diagnosis of primary angiitis of the central nervous system: a single-center retrospective study. J Rheumatol. 2012;39(5):1026-34 https://doi.org/10.3899/jrheum.110707.

121. Beuker C, Schmidt A, Strunk D, Sporns PB, Wiendl H, Meuth SG, et al. Primary angiitis of the central nervous system: diagnosis and treatment. Ther Adv Neurol Disord. 2018;11:175628641878507 https://doi.org/10.1177/1 756286418785071.

122. Giannini C, Salvarani C, Hunder G. Brown RD Primary central nervous system vasculitis: pathology and mechanisms. Acta Neuropathol. 2012;123(6):75972 https://doi.org/10.1007/s00401-012-0973-9.

123. Topcuoglu MA, Jha RM, George J, Frosch MP, Singhal AB. Hemorrhagic primary CNS angiitis and vasoconstrictive drug exposure. Neurol Clin Pract. 2017;7(1):26-34 https://doi.org/10.1212/CPJ.0000000000000324.

124. Becatti M, Emmi G, Bettiol A, Silvestri E, Di Scala G, Taddei N, et al. Behçet's syndrome as a tool to dissect the mechanisms of thrombo-inflammation: clinical and pathogenetic aspects. Clin Exp Immunol. 2019;195(3):322-33 https://doi.org/10.1111/cei.13243.

125. Peleg H, Ben-Chetrit E. Vasculitis in the autoinflammatory diseases. Curr Opin Rheumatol. 2017;29(1):4-11 https://doi.org/10.1097/BOR. 0000000000000347

126. Hirohata S. Histopathology of central nervous system lesions in Behçet's disease. J Neurol Sci. 2008;267(1-2):41-7 https://doi.org/10.1016/j.jns.2007.09. 041.

127. Chambers JC, Haskard DO, Kooner JS. Vascular endothelial function and oxidative stress mechanism in patients with Behçet's syndrome. J Am Coll Cardiol. 2001;37(2):517-20 https://doi.org/10.1016/50735-1097(00)01137-2.

128. Van der Houwen T, van Laar J. Behçet's disease, and the role of TNF- $a$ and TNF-a blockers. Int J Mol Sci. 2020;21(9):3072 https://doi.org/10.3390/ijms21 093072

129. Brunner J, Feldman BM, Tyrrell PN, Kuemmerle-Deschner JB, Zimmerhackl LB, Gassner I, et al. Takayasu arteritis in children and adolescents. Rheumatology (Oxford). 2010:49:1806-14.

130. Li-xin Z, Jun N, Shan G, Bin P, Li-ying C. Neurological manifestations of Takayasu arteritis. Chin Med Sci J. 2011;26(4):227-30 https://doi.org/10.1016/ s1001-9294(12)60005-4.

131. Provenzale JM, Allen NB. Neuroradiologic findings in polyarteritis nodosa. AJNR Am J Neuroradiol. 1996;17(6):1119-26.

132. Frayha RA, Abu-Haidar F. Polyarteritis nodosa masquerading as temporal arteritis. J Rheumatol. 1979;6(1):76-9.

133. Walz LeBlanc BA, Keystone EC, Feltis JT, Geddie WR, Lie JT. Polyarteritis nodosa clinically masquerading as temporal arteritis with lymphadenopathy. J Rheumatol. 1994;21(5):949-52.

134. Highton J, Anderson KR. Concurrent polyarteritis nodosa and temporal arteritis. N Z Med J. 1984;97(767):766-7.

135. Généreau T, Lortholary O, Pottier MA, Michon-Pasturel U, Ponge T, de Wazières B, et al. Temporal artery biopsy: a diagnostic tool for systemic necrotizing vasculitis. French Vasculitis Study Group. Arthritis Rheum. 1999; 42:2674-81

136. Watanabe R, Berry GJ, Liang DH, Goronzy JJ, Weyand CM. Pathogenesis of giant cell arteritis and takayasu arteritis-similarities and differences. Curr Rheumatol Rep. 2020;22(10):68 https://doi.org/10.1007/s11926-020-00948-x.

137. Gao N, Cui W, Zhao LM, Li TT, Zhang JH, Pan LL. Contribution of Th2-like Treg cells to the pathogenesis of Takayasu's arteritis. Clin Exp Rheumatol. 2020;38(Suppl 124(2)):48-54.

138. Li T, Gao N, Cui W, Zhao L, Pan L. Natural killer cells and their function in Takayasu's arteritis. Clin Exp Rheumatol. 2020;38(Suppl 124(2)):84-90.

139. Savioli B, Abdulahad WH, Brouwer E, Kallenberg CGM, de Souza AWS. Are cytokines and chemokines suitable biomarkers for Takayasu arteritis? Autoimmun Rev. 2017;16(10):1071-8 https://doi.org/10.1016/j.autrev.2017.07. 023.

140. Régnier P, Le Joncour A, Maciejewski-Duval A, Desbois AC, Comarmond C, Rosenzwajg M, et al. Targeting JAK/STAT pathway in Takayasu's arteritis. Ann Rheum Dis. 2020;79(7):951-9 https://doi.org/10.1136/annrheumdis-201 9-216900.

141. Michailidou D, Rosenblum JS, Rimland CA, Marko J, AhIman MA, Grayson PC. Clinical symptoms and associated vascular imaging findings in 
Takayasu's arteritis compared to giant cell arteritis. Ann Rheum Dis. 2020; 79(2):262-7 https://doi.org/10.1136/annrheumdis-2019-216145.

142. Cakar N, Yalcinkaya F, Duzova A, Caliskan S, Sirin A, Oner A, et al. Takayasu arteritis in children. J Rheumatol. 2008;35(5):913-9.

143. Chaudhry MA, Latif F. Takayasu's arteritis and its role in causing renal artery stenosis. Am J Med Sci. 2013;346(4):314-8 https://doi.org/10.1097/MAJ. 0b013e31827e5dad.

144. Kivity S, Agmon-Levin N, Zandman-Goddard G, Chapman J, Shoenfeld Y. Neuropsychiatric lupus: a mosaic of clinical presentations. BMC Med. 2015; 4(13):43.

145. Carrión-Barberà I, Salman-Monte TC, Vílchez-Oya F, Monfort J. Neuropsychiatric involvement in systemic lupus erythematosus: a review. Autoimmun Rev. 2021; 20(4):102780 https://doi.org/10.1016/j.autrev.2021.102780.

146. Unterman A, Nolte JE, Boaz M, Abady M, Shoenfeld Y, Zandman-Goddard G. Neuropsychiatric syndromes in systemic lupus erythematosus: a metaanalysis. Semin Arthritis Rheum. 2011;41(1):1-11 https://doi.org/10.1016/j. semarthrit.2010.08.001.

147. Gonçalves MJ, Sousa S, Inês LS, Duarte C, Borges J, Silva C, et al. Characterization of damage in Portuguese lupus patients: analysis of a national lupus registry. Lupus. 2015;24(3):256-62 https://doi.org/10.1177/ 0961203314555172.

148. Mikdashi J, Handwerger B. Predictors of neuropsychiatric damage in systemic lupus erythematosus: data from the Maryland lupus cohort. Rheumatology (Oxford). 2004;43(12):1555-60 https://doi.org/10.1093/ rheumatology/keh384.

149. Bombardier C, Gladman DD, Urowitz MB, Caron D, Chang CH. Derivation of the SLEDAI. A disease activity index for lupus patients. The Committee on Prognosis Studies in SLE. Arthritis Rheum. 1992;35(6):630-40 https://doi. org/10.1002/art.1780350606.

150. Brandt KD, Lessell S. Migrainous phenomena in systemic lupus erythematosus. Arthritis Rheum. 1978;21 (1):7-16 https://doi.org/10.1002/art.1 780210103.

151. Isenberg DA, Meyrick-Thomas D, Snaith ML, McKeran RO, Royston JP. A study of migraine in systemic lupus erythematosus. Ann Rheum Dis. 1982; 41(1):30-2 https://doi.org/10.1136/ard.41.1.30.

152. SLevine SR, Joseph R, D'Andrea G, Welch KM. Migraine and the lupus anticoagulant. Case reports and review of the literature. Cephalalgia. 1987; 7(2):93-9 https://doi.org/10.1046/.1468-2982.1987.0702093.x.

153. Anzola GP, Dalla Volta G, Balestrieri G. Headache in patients with systemic lupus erythematosus: clinical and telethermographic findings. Arch Neurol. 1988:45(10):1061-2 https://doi.org/10.1001/archneur.1988.00520340015003.

154. Vázquez-Cruz J, Traboulssi H, Rodriquez-De la Serna A, Geli C, Roig C, Diaz C. A prospective study of chronic or recurrent headache in systemic lupus erythematosus. Headache. 1990;30(4):232-5 https://doi.org/10.1111/j.1526-4 610.1990.hed3004232.x.

155. Markus HS, Hopkinson N. Migraine and headache in systemic lupus erythematosus and their relationship with antibodies against phospholipids. J Neurol. 1992;239(1):39-42 https://doi.org/10.1007/BF00839210.

156. Montalbán J, Cervera R, Font J, Ordi J, Vianna J, Haga HJ, et al. Lack of association between anticardiolipin antibodies and migraine in systemic lupus erythematosus. Neurology. 1992;42(3):681-2 https://doi.org/10.1212/ WNL.42.3.681.

157. Hietaharju A, Jäntti V, Korpela M, Frey H. Nervous system involvement in systemic lupus erythematosus, Sjögren syndrome and scleroderma. Acta Neurol Scand. 1993;88(4):299-308 https://doi.org/10.1111/j.1600-0404.1993. tb04241.x.

158. Omdal R, Waterloo K, Koldingsnes W, Husby G, Mellgren SI. Somatic and psychological features of headache in systemic lupus erythematosus. $J$ Rheumatol. 2001;28(4):772-9.

159. Ainiala H, Loukkola J, Peltola J, Korpela M, Hietaharju A. The prevalence of neuropsychiatric syndromes in systemic lupus erythematosus. Neurology. 2001;57(3):496-500 https://doi.org/10.1212/WNL.57.3.496.

160. Fernández-Nebro A, Palacios-Muñoz R, Gordillo J, Abarca-Costalago M, De Haro-Liger M, Rodríguez-Andreu J, et al. Chronic or recurrent headache in patients with systemic lupus erythematosus: a case control study. Lupus. 1999:8(2):151-6 https://doi.org/10.1191/096120399678847443.

161. Ainiala H, Hietaharju A, Loukkola J, Peltola J, Korpela M, Metsänoja R, et al. Validity of the new American College of Rheumatology criteria for neuropsychiatric lupus syndromes: a population-based evaluation. Arthritis Rheum. 2001:45(5):419-23 https://doi.org/10.1002/1529-0131(200110)45:5< 419::AID-ART360>3.0.CO;2-X.
162. Sfikakis PP, Mitsikostas DD, Manoussakis MN, Foukaneli D, Moutsopoulos HM. Headache in systemic lupus erythematosus: a controlled study. $\mathrm{Br} J$ Rheumatol. 1998;37(3):300-3 https://doi.org/10.1093/rheumatology/37.3.300.

163. Glanz BI, Venkatesan A, Schur PH, Lew RA, Khoshbin S. Prevalence of migraine in patients with systemic lupus erythematosus. Headache. 2001; 41(3):285-9 https://doi.org/10.1046/j.1526-4610.2001.111006285.x.

164. Whitelaw DA, Hugo F, Spangenberg JJ, Rickman R. Headaches in patients with systemic lupus erythematosus: a comparative study. Lupus. 2004;13(7): 501-5 https://doi.org/10.1191/0961203304lu1050oa.

165. Lessa B, Santana A, Lima I, Almeida JM, Santiago M. Prevalence and classification of headache in patients with systemic lupus erythematosus. Clin Rheumatol. 2006;25(6):850-3 https://doi.org/10.1007/s10067-005-0186-X.

166. Katsiari CG, Vikelis M, Paraskevopoulou ES, Sfikakis PP, Mitsikostas DD. Headache in systemic lupus erythematosus vs multiple sclerosis: a prospective comparative study. Headache. 2011;51(9):1398-407 https://doi. org/10.1111/j.1526-4610.2011.01962.x.

167. Badry R, Gamal RM. Different types of headache in patients with systemic lupus erythematosus. Int J Neurosci. 2015;125(5):357-60 https://doi.org/10.31 09/00207454.2014.951041.

168. Magro CE, Cordeiro E, Bezerra Neto F, Silva MB, Skare T. Headache in lupus: no correlation between migraine, Raynaud and anticardiolipin antibodies. Rev Méd Paraná. 2002;60:5-7.

169. Atkinson RA, Appenzeller $O$. Headache in small vessel disease of the brain: a study of patients with systemic lupus erythematosus. Headache. 1975;15(3): 198-201 https://doi.org/10.1111/j.1526-4610.1975.hed1503198.x.

170. Mitsikostas DD, Sfikakis PP, Goadsby PJ. A meta-analysis for headache in systemic lupus erythematosus: the evidence and the myth. Brain. 2004; 127(5):1200-9 https://doi.org/10.1093/brain/awh146.

171. Santos FPST, Nascimento BR, Calderaro DC, Ferreira GA, Correa H. Neuropsychiatric Syndromes in Childhood-Onset Systemic Lupus Erythematosus: A Systematic Review and Meta-analysis. J Clin Rheumatol. 2021;27(5):206-14 https://doi.org/10.1097/RHU.0000000000001029.

172. Hanly JG, Urowitz MB, O'Keeffe AG, Gordon C, Bae SC, Sanchez-Guerrero J, et al. Headache in systemic lupus erythematosus: results from a prospective, international inception cohort study. Arthritis Rheum. 2013;65:2887-97.

173. Amit M, Molad Y, Levy O, Wysenbeek AJ. Headache in systemic lupus erythematosus and its relation to other disease manifestations. Clin Exp Rheumatol. 1999:17(4):467-70.

174. Appenzeller S, Costallat LT. Clinical implications of migraine in systemic lupus erythematosus: relation to cumulative organ damage. Cephalalgia. 2004;24(12):1024-30. https://doi.org/10.1111/j.1468-2982.2004.00785.x.

175. Zandman-Goddard G, Chapman J, Shoenfeld Y. Autoantibodies involved in neuropsychiatric SLE and antiphospholipid syndrome. Semin Arthritis Rheum. 2007:36(5):297-315 https://doi.org/10.1016/.semarthrit.2006.11.003.

176. Ho RC, Thiaghu C, Ong H, Lu Y, Ho CS, Tam WW, et al. A meta-analysis of serum and cerebrospinal fluid autoantibodies in neuropsychiatric systemic lupus erythematosus. Autoimmun Rev. 2016;15(2):124-38 https://doi.org/1 0.1016/j.autrev.2015.10.003

177. Faust TW, Chang EH, Kowal C, Berlin R, Gazaryan IG, Bertini E, et al. Neurotoxic lupus autoantibodies alter brain function through two distinct mechanisms. Proc Natl Acad Sci U S A. 2010;107(43):18569-74 https://doi. org/10.1073/pnas. 1006980107.

178. Tsuchiya H, Haga S, Takahashi Y, Kano T, Ishizaka Y, Mimori A. Identification of novel autoantibodies to $G A B A(B)$ receptors in patients with neuropsychiatric systemic lupus erythematosus. Rheumatology (Oxford). 2014;53:1219-28.

179. Toubi E, Shoenfeld Y. Clinical and biological aspects of anti-P-ribosomal protein autoantibodies. Autoimmun Rev. 2007;6(3):119-25 https://doi.org/1 0.1016/j.autrev.2006.07.004.

180. Yoshio T, Okamoto H, Hirohata S, Minota S. IgG anti-NR2 glutamate receptor autoantibodies from patients with systemic lupus erythematosus activate endothelial cells. Arthritis Rheum. 2013;65(2):457-63 https://doi.org/10.1 002/art.37745.

181. Hawro T, Bogucki A, Krupińska-Kun M, Maurer M, Woźniacka A. Intractable headaches, ischemic stroke, and seizures are linked to the presence of anti$\beta 2 \mathrm{GPI}$ antibodies in patients with systemic lupus erythematosus. PLoS One. 2015;10(3):e0119911 https://doi.org/10.1371/journal.pone.0119911.

182. Duarte-Delgado NP, Vásquez G, Ortiz-Reyes BL. Blood-brain barrier disruption and neuroinflammation as pathophysiological mechanisms of the diffuse manifestations of neuropsychiatric systemic lupus 
erythematosus. Autoimmun Rev. 2019;18(4):426-32 https://doi.org/10.1016/ j.autrev.2018.12.004.

183. Fragoso-Loyo H, Atisha-Fregoso Y, Llorente L, Sánchez-Guerrero J. Inflammatory profile in cerebrospinal fluid of patients with headache as a manifestation of neuropsychiatric systemic lupus erythematosus. Rheumatology (Oxford). 2013;52:2218-22.

184. Bicakci S, Ozbek S, Bicakci K, Aslan K, Kara B, Sarica Y. Recurrent headache and MRI findings in systemic lupus erythematosus. J Natl Med Assoc. 2008; 100(3):323-6 https://doi.org/10.1016/S0027-9684(15)31245-1.

185. Tjensvoll AB, Lauvsnes MB, Hirohata S, Beyer MK, Greve OJ, Kvivik I, et al. Migraine in patients with systemic lupus erythematosus is associated with reduced cerebral grey matter volume but not with measures of glial activation or anti-NR2 or anti-P antibodies. Eur J Neurol. 2016;23(4):780-6 https://doi.org/10.1111/ene.12946.

186. Son CN, Kim SH, Chang HW, Kim JM. A neurometabolite study of chronic daily headache in patients with systemic lupus erythematosus using magnetic resonance spectroscopy: comparison with fibromyalgia patients and healthy controls. Kor J Intern Med. 2016;31(6):1171-7 https://doi.org/1 0.3904/kjim.2015.196

187. Hanly JG, Barber C. Insight into SLE-related migraine using brain singlephoton-emission computed tomography. Nat Clin Pract Rheumatol. 2007; 3(4):200-1 https://doi.org/10.1038/ncprheum0453.

188. Nobili F, Mignone A, Rossi E, Morbelli S, Piccardo A, Puppo F, et al. Migraine during systemic lupus erythematosus: findings from brain single photon emission computed tomography. J Rheumatol. 2006;33(11):2184-91.

189. Bayetto K, Logan RM. Sjögren's syndrome: a review of aetiology, pathogenesis, diagnosis and management. Aust Dent J. 2010;55(Suppl 1): 39-47 https://doi.org/10.1111/j.1834-7819.2010.01197.x.

190. Peri Y, Agmon-Levin N, Theodor E, Shoenfeld Y. Sjögren's syndrome, the old and the new. Best Pract Res Clin Rheumatol. 2012;26(1):105-17 https://doi. org/10.1016/j.berh.2012.01.012.

191. Mavragani CP, Moutsopoulos HM. The geoepidemiology of Sjögren's syndrome. Autoimmun Rev. 2010;9(5):A305-10 https://doi.org/10.1016/j.a utrev.2009.11.004.

192. Birnbaum J. Peripheral nervous system manifestations of Sjögren syndrome: clinical patterns, diagnostic paradigms, etiopathogenesis, and therapeutic strategies. Neurologist. 2010;6:287-97.

193. Delalande S, de Seze J, Fauchais AL, Hachulla E, Stojkovic T, Ferriby D, et al. Neurologic manifestations in primary Sjögren syndrome: a study of 82 patients. Medicine. 2004;83:280-91.

194. Segal B, Carpenter A, Walk D. Involvement of nervous system pathways in primary Sjögren's syndrome. Rheum Dis Clin N Am. 2008;34(4):885-906, viii. https://doi.org/10.1016/j.rdc.2008.08.001.

195. Vitali C, Bombardieri S, Jonsson R, Moutsopoulos HM, Alexander EL, Carsons $\mathrm{SE}$, et al. Classification criteria for Sjögren's syndrome: a revised version of the European criteria proposed by the American-European Consensus Group. Ann Rheum Dis. 2002;61:554-8.

196. Morreale M, Marchione P, Giacomini P, Pontecorvo S, Marianetti M, Vento C, et al. Neurological involvement in primary Sjögren syndrome: a focus on central nervous system. PLoS One. 2014;9(1):e84605 https://doi.org/10.1371/ journal.pone.0084605.

197. Carvajal Alegria G, Guellec D, Mariette X, Gottenberg JE, Dernis E, Dubost JJ, et al. Epidemiology of neurological manifestations in Sjögren's syndrome: data from the French ASSESS Cohort. RMD Open. 2016;20(2):e000179.

198. Teixeira F, Moreira I, Silva AM, Vasconcelos C, Farinha F, Santos E. Neurological involvement in Primary Sjögren Syndrome. Acta Reumatol Port. 2013;38(1):29-36.

199. Bougea A, Anagnostou E, Giatas K, Paraskevas G, Triantafyllou N, Kararizou E. Corrigendum to "A Systematic Review of Peripheral and Central Nervous System Involvement of Rheumatoid Arthritis, Systemic Lupus Erythematosus, Primary Sjögren's Syndrome, and Associated Immunological Profiles". Int J Chronic Dis. 2016;2016:9854813 https://doi.org/10.1155/2016/9854813.

200. Kassan SS, Moutsopoulos HM. Clinical manifestations and early diagnosis of Sjögren syndrome. Arch Intern Med. 2004;28(164):1275-84.

201. Massara A, Bonazza S, Castellino G, Caniatti L, Trotta F, Borrelli M, et al. Central nervous system involvement in Sjögren's syndrome: unusual, but not unremarkable--clinical, serological characteristics and outcomes in a large cohort of Italian patients. Rheumatology (Oxford). 2010;49:1540-9.

202. Pal B, Gibson C, Passmore J, Griffiths ID, Dick WC. A study of headaches and migraine in Sjögren's syndrome and other rheumatic disorders. Ann Rheum Dis. 1989;48(4):312-6 https://doi.org/10.1136/ard.48.4.312.
203. Gökçay F, Oder G, Celebisoy N, Gökçay A, Sirin H, Kabasakal Y. Headache in primary Sjögren's syndrome: a prevalence study. Acta Neurol Scand. 2008; 118(3):189-92 https://doi.org/10.1111/j.1600-0404.2008.00997.x.

204. Tjensvoll AB, Harboe E, Gøransson LG, Beyer MK, Greve OJ, Kvaløy JT, et al. Headache in primary Sjøgren's syndrome: a population-based retrospective cohort study. Eur J Neurol. 2013;20(3):558-63 https://doi.org/10.1111/ene.12033.

205. Koktekir BE, Celik G, Karalezli A, Kal A. Dry eyes and migraines: is there really a correlation? Cornea. 2012;31(12):1414-6 https://doi.org/10.1097/ICO.0b013 e318247ec2a.

206. Celikbilek A, Adam M. The relationship between dry eye and migraine. Acta Neurol Belg. 2015;115(3):329-33 https://doi.org/10.1007/s13760-014-0359-y.

207. Sarac O, Kosekahya P, Yildiz Tasci Y, Keklikoglu HD, Deniz O, Erten \$̧, et al. The Prevalence of Dry Eye and Sjögren Syndrome in Patients with Migraine. Ocul Immunol Inflamm. 2017;25(3):370-5 https://doi.org/10.3109/09273948.2 015.1132739 .

208. Alunno A, Carubbi F, Bartoloni E, Cipriani P, Giacomelli R, Gerli R. The kaleidoscope of neurological manifestations in primary Sjögren's syndrome. Clin Exp Rheumatol. 2019;37(Suppl 118(3)):192-8.

209. Govoni M, Padovan M, Rizzo N, Trotta F. CNS involvement in primary Sjögren's syndrome: prevalence, clinical aspects, diagnostic assessment and therapeutic approach. CNS Drugs. 2001;15(8):597-607 https://doi.org/10.21 65/00023210-200115080-00003

210. Escudero D, Latorre P, Codina M, Coll-Cantí J, Coll J. Central nervous system disease in Sjögren's syndrome. Ann Med Interne. 1995;146(4):239-42.

211. Goldberg NC, Duncan SC, Winkelmann RK. Migraine and systemic scleroderma. Arch Dermatol. 1978;114(4):550-1 https://doi.org/10.1001/a rchderm.1978.01640160028008.

212. Amaral TN, Peres FA, Lapa AT, Marques-Neto JF, Appenzeller S. Neurologic involvement in scleroderma: a systematic review. Semin Arthritis Rheum. 2013;43(3):335-47 https://doi.org/10.1016/j.semarthrit.2013.05.002.

213. Le H, Tfelt-Hansen P, Russell MB, Skytthe A, Kyvik KO, Olesen J. Co-morbidity of migraine with somatic disease in a large population-based study. Cephalalgia. 2011;31(1):43-64 https://doi.org/10.1177/0333102410373159.

214. Kalaydjian A, Merikangas K. Physical and mental comorbidity of headache in a nationally representative sample of US adults. Psychosom Med. 2008;70(7): 773-80 https://doi.org/10.1097/PSY.0b013e31817f9e80.

215. Wang YC, Huang YP, Wang MT, Wang HI, Pan SL. Increased risk of rheumatoid arthritis in patients with migraine: a population-based, propensity score-matched cohort study. Rheumatol Int. 2017;37(2):273-9 https://doi.org/10.1007/s00296-016-3604-2.

216. Uluduz D, Tavsanli ME, Uygunoğlu U, Saip S, Kasapcopur O, Ozge A, et al. Primary headaches in pediatric patients with chronic rheumatic disease. Brain and Development. 2014;36(10):884-91 https://doi.org/10.1016/j.bra indev.2014.01.009

217. Zeller J, Weissbarth E, Baruth B, Mielke H, Deicher H. Serotonin content of platelets in inflammatory rheumatic diseases. Correlation with clinical activity. Arthritis Rheum. 1983;26(4):532-40 https://doi.org/10.1002/art.1780260413.

218. Sacre S, Medghalchi M, Gregory B, Brennan F, Williams R. Fluoxetine and citalopram exhibit potent antiinflammatory activity in human and murine models of rheumatoid arthritis and inhibit toll-like receptors. Arthritis Rheum. 2010;62(3):683-93 https://doi.org/10.1002/art.27304.

219. Kling A, Seddighzadeh M, Arlestig L, Alfredsson L, Rantapää-Dahlqvist S, Padyukov L. Genetic variations in the serotonin 5-HT2A receptor gene (HTR2A) are associated with rheumatoid arthritis. Ann Rheum Dis. 2008; 67(8):1111-5 https://doi.org/10.1136/ard.2007.074948.

220. Danese E, Montagnana M, Lippi G. Platelets and migraine. Thromb Res. 2014;134(1):17-22 https://doi.org/10.1016/j.thromres.2014.03.055.

221. Saengjaroentham C, Supornsilpchai W, Ji-Au W, Srikiatkhachorn A, Maneesrile GS. Serotonin depletion can enhance the cerebrovascular responses induced by cortical spreading depression via the nitric oxide pathway. Int J Neurosci. 2015;125(2):130-9 https://doi.org/10.3109/00207454.2014.908876.

222. Tenedios F, Erkan D, Lockshin MD. Cardiac involvement in the antiphospholipid syndrome. Lupus. 2005;14(9):691-6 https://doi.org/10.11 91/0961203305lu2202oa.

223. Kaushik S, Federle MP, Schur PH, Krishnan M, Silverman SG, Ros PR. Abdominal thrombotic and ischemic manifestations of the antiphospholipid antibody syndrome: CT findings in 42 patients. Radiology. 2001;218(3):768-71 https://doi.org/10.1148/radiology.218.3.r01fe43768.

224. Branch DW, Khamashta MA. Antiphospholipid syndrome: obstetric diagnosis, management, and controversies. Obstet Gynecol. 2003;101(6): 1333-44 https://doi.org/10.1016/s0029-7844(03)00363-6. 
225. Noureldine MH, Khamashta MA, Merashli M, Sabbouh T, Hughes GR, Uthman I. Musculoskeletal manifestations of the antiphospholipid syndrome. Lupus. 2016;25(5):451-62 https://doi.org/10.1177/0961203316636467.

226. Arvieux J, Darnige L, Caron C, Reber G, Bensa JC, Colomb MG. Development of an ELISA for autoantibodies to prothrombin showing their prevalence in patients with lupus anticoagulants. Thromb Haemost. 1995;74(4):1120-5.

227. Atsumi T, leko M, Bertolaccini ML, Ichikawa K, Tsutsumi A, Matsuura E, et al. Association of autoantibodies against the phosphatidylserine-prothrombin complex with manifestations of the antiphospholipid syndrome and with the presence of lupus anticoagulant. Arthritis Rheum. 2000;43(9):1982-93 https://doi.org/10.1002/1529-0131(200009)43:9<1982::AID-ANR9>3.0.CO;2-2.

228. Miyakis S, Lockshin MD, Atsumi T, Branch DW, Brey RL, Cervera R, et al. International consensus statement on an update of the classification criteria for definite antiphospholipid syndrome (APS). J Thromb Haemost. 2006;4(2): 295-306 https://doi.org/10.1111/j.1538-7836.2006.01753.x.

229. Cervera R, Boffa MC, Khamashta MA, Hughes GR. The Euro-Phospholipid project: epidemiology of the antiphospholipid syndrome in Europe. Lupus. 2009;18(10):889-93 https://doi.org/10.1177/0961203309106832.

230. Sanna G, Bertolaccini ML, Cuadrado MJ, Khamashta MA, Hughes GR. Central nervous system involvement in the antiphospholipid (Hughes) syndrome. Rheumatology (Oxford). 2003;42(2):200-13 https://doi.org/10.1093/rheuma tology/keg080.

231. Schofield JR, Blitshteyn S, Shoenfeld Y, Hughes GR. Postural tachycardia syndrome (POTS) and other autonomic disorders in antiphospholipid (Hughes) syndrome (APS). Lupus. 2014;23(7):697-702 https://doi.org/10.11 77/0961203314524468

232. Iñiguez C, Pascual C, Pardo A, Martinez-Castrillo JC, Alvarez-Cermeño JC. Antiphospholipid antibodies in migraine. Headache. 1991;31(10):666-8 https://doi.org/10.1111/j.1526-4610.1991.hed3110666.x.

233. Robbins L. Migraine and anticardiolipin antibodies--case reports of 13 patients, and the prevalence of antiphospholipid antibodies in migraineurs. Headache. 1991;31(8):537-9 https://doi.org/10.1111/j.1526-4610.1991.hed31 08537.x.

234. Tietjen GE. Migraine and antiphospholipid antibodies. Cephalalgia. 1992; 12(2):69-74 https://doi.org/10.1046/j.1468-2982.1992.1202069.x.

235. Intiso D, Crociani P, Fogli D, Grandone E, Cappucci G, Di Rienzo F, et al. Occurrence of factor $V$ Leiden mutation (Arg506GIn) and anticardiolipin antibodies in migraine patients. Neurol Sci. 2002;22(6):455-8 https://doi. org/10.1007/s100720200005.

236. Avcin T, Markelj G, Niksic V, Rener-Primec Z, Cucnik S, Zupancic M, et al. Estimation of antiphospholipid antibodies in a prospective longitudinal study of children with migraine. Cephalalgia. 2004;24(10):831-7 https://doi. org/10.1111/j.1468-2982.2004.00752.x.

237. Cavestro C, Micca G, Molinari F, Bazzan M, DI Pietrantonj C, Aloi R, et al. Migraineurs show a high prevalence of antiphospholipid antibodies. J Thromb Haemost. 2011;9(7):1350-4 https://doi.org/10.1111/j.1538-7836.2011.04348.x.

238. Pilarska E, Lemka M, Bakowska A. Przeciwciała antyfosfolipidowe w migrenie $\mathrm{u}$ dzieci [Antiphospholipid antibodies in children with migraine]. Neurol Neurochir Pol. 2006:40(4):291-6.

239. Angelini L, Zibordi F, Zorzi G, Nardocci N, Caporali R, Ravelli A, et al. Neurological disorders, other than stroke, associated with antiphospholipid antibodies in childhood. Neuropediatrics. 1996;27(03):149-53 https://doi. org/10.1055/s-2007-973766.

240. Hogan MJ, Brunet DG, Ford PM, Lillicrap D. Lupus anticoagulant, antiphospholipid antibodies and migraine. Can J Neurol Sci. 1988;15(4):420-5 https://doi.org/10.1017/S0317167100028183.

241. Tsakiris DA, Kappos L, Reber G, Marbet GA, Le Floch-Rohr J, Roux E, et al. Lack of association between antiphospholipid antibodies and migraine. Thromb Haemost. 1993;69(5):415-7.

242. Paule R, Morel N, Le Guern V, Fredi M, Coutte L, Belhocine M, et al. Classification of primary antiphospholipid syndrome as systemic lupus erythematosus: analysis of a cohort of 214 patients. Autoimmun Rev. 2018 17(9):866-72 https://doi.org/10.1016/j.autrev.2018.03.011.

243. Pardos-Gea J, Ordi-Ros J, Avegliano G, Cortés-Hernández J, Balada E, Evangelista A, et al. Echocardiography at diagnosis of antiphospholipid syndrome provides prognostic information on valvular disease evolution and identifies two subtypes of patients. Lupus. 2010;19(5):575-82 https:// doi.org/10.1177/0961203309353772.

244. Kalashnikova LA. Non-ischemic neurological manifestations in patients with primary antiphospholipid syndrome. Zh Nevrol Psikhiatr Im S S Korsakova. 2005; 105:18-23
245. Honczarenko K, Budzianowska A, Ostanek L. Neurological syndromes in systemic lupus erythematosus and their association with antiphospholipid syndrome. Neurol Neurochir Pol. 2008;42(6):513-7.

246. Stojanovich L, Kontic M, Djokovic A, Marisavljevic D, Ilijevski N, Stanisavljevic $\mathrm{N}$, et al. Association between systemic non-criteria APS manifestations and antibody type and level: results from the Serbian national cohort study. Clin Exp Rheumatol. 2013;31(2):234-42.

247. Hughes GR. Antiphospholipid syndrome, migraine and stroke. Lupus. 2010; 19(5):555-6 https://doi.org/10.1177/0961203309358186.

248. Cuadrado MJ, Khamashta MA, Hughes GR. Sticky blood and headache. Lupus. 2001;10(6):392-3 https://doi.org/10.1191/096120301678646119.

249. Cuadrado MJ, Khamashta MA, Hughes GR. Migraine and stroke in young women. QJM. 2000;93(5):317-8. https://doi.org/10.1093/qjmed/93.5.317 PMID: 10825409

250. Zhu DS, Fu J, Zhang Y, Li SX, Zhang GX, Guan YT, et al. Neurological antiphospholipid syndrome: clinical, neuroimaging, and pathological characteristics. J Neurol Sci. 2014;346(1-2):138-44 https://doi.org/10.1016/j. jns.2014.08.010.

251. Verrotti A, Cieri F, Pelliccia P, Morgese G, Chiarelli F. Lack of association between antiphospholipid antibodies and migraine in children. Int J Clin Lab Res. 2000;30(2):109-11 https://doi.org/10.1007/s005990070023.

252. Williams FM, Cherkas LF, Bertolaccini ML, Murru V, Surdulescu GL, Hughes GR, et al. Migraine and antiphospholipid antibodies: no association found in migraine-discordant monozygotic twins. Cephalalgia. 2008;28(10):1048-52 https://doi.org/10.1111/j.1468-2982.2008.01646.x.

253. Islam MA, Alam F, Gan SH, Cavestro C, Wong KK. Coexistence of antiphospholipid antibodies and cephalalgia. Cephalalgia. 2018 Mar;38(3): 568-80. https://doi.org/10.1177/0333102417694881.

254. Carecchio M, Cantello R, Comi C. Revisiting the molecular mechanism of neurological manifestations in antiphospholipid syndrome: beyond vascular damage. J Immunol Res. 2014;2014:239398.

255. Erkan D, Aguiar CL, Andrade D, Cohen H, Cuadrado MJ, Danowski A, et al. 14th International Congress on Antiphospholipid Antibodies: task force report on antiphospholipid syndrome treatment trends. Autoimmun Rev. 2014;13(6):685-96 https://doi.org/10.1016/j.autrev.2014.01.053.

256. Hughes GR. Migraine, memory loss, and "multiple sclerosis". Neurological features of the antiphospholipid (Hughes') syndrome. Postgrad Med J. 2003; 79(928):81-3 https://doi.org/10.1136/pmj.79.928.81.

257. Thonnard-Neumann E. Migraine therapy with heparin: pathophysiologic basis. Headache. 1977;16(6):284-92 https://doi.org/10.1111/j.1526-4610.1976. hed1606284.x

258. Asherson RA, Giampaulo D, Singh S, Sulman L. Dramatic response of severe headaches to anticoagulation in a patient with antiphospholipid syndrome. J Clin Rheumatol. 2007;13(3):173-4 https://doi.org/10.1097/RHU.0b013e31 80690 af6.

259. King $E$, Odette W. Complex migraine with subtherapeutic INR in antiphospholipid syndrome. Am J Med. 2012;125(11):e9-10 https://doi.org/1 0.1016/j.amjmed.2012.03.003

260. Aamodt AH, Stovner L, Midthjell K, Hagen K, Zwart JA. Headache prevalence related to diabetes mellitus. The Head-HUNT study. Eur J Neurol. 2007;14(7):738-44 https://doi.org/10.1111/j.1468-1331.2007.01765.x.

261. Hagen K, Åsvold BO, Midthjell K, Stovner LJ, Zwart JA, Linde M. Inverse relationship between type 1 diabetes mellitus and migraine. Data from the Nord-Trøndelag Health Surveys 1995-1997 and 2006-2008. Cephalalgia. 2018;38(3):417-26 https://doi.org/10.1177/0333102417690488.

262. Rubino E, Rainero I, Garino F, Vicentini C, Govone F, Vacca A, et al. Subclinical hypothyroidism is associated with migraine: a case-control study. Cephalalgia. 2019;39(1):15-20 https://doi.org/10.1177/0333102418769917.

263. Fallah R, Mirouliaei M, Bashardoost N, Partovee M. Frequency of subclinical hypothyroidism in 5- to 15-year-old children with migraine headache. J Pediatr Endocrinol Metab. 2012;25(9-10):859-62 https://doi.org/10.1515/ jpem-2012-0121.

264. Martin AT, Pinney SM, Xie C, Herrick RL, Bai Y, Buckholz J, et al. Headache disorders may be a risk factor for the development of new onset hypothyroidism. Headache. 2017;57(1):21-30 https://doi.org/10.1111/head.12 943.

265. Doulberis M, Saleh C, Beyenburg S. Is there an association between migraine and gastrointestinal disorders? J Clin Neurol. 2017;13(3):215-26 https://doi.org/10.3988/jen.2017.13.3.215.

266. Bähler C, Schoepfer AM, Vavricka SR, Brüngger B, Reich O. Chronic comorbidities associated with inflammatory bowel disease: prevalence and 
impact on healthcare costs in Switzerland. Eur J Gastroenterol Hepatol. 2017;29(8):916-25 https://doi.org/10.1097/MEG.0000000000000891.

267. Cámara-Lemarroy CR, Rodriguez-Gutierrez R, Monreal-Robles R, Marfil-Rivera A. Gastrointestinal disorders associated with migraine: a comprehensive review. World J Gastroenterol. 2016;28(22):8149-60.

268. Bürk K, Farecki ML, Lamprecht G, Roth G, Decker $P$, Weller $M$, et al. Neurological symptoms in patients with biopsy proven celiac disease. Mov Disord. 2009;24(16):2358-62 https://doi.org/10.1002/mds.22821.

269. Dimitrova AK, Ungaro RC, Lebwohl B, Lewis SK, Tennyson CA, Green MW, et al. Prevalence of migraine in patients with celiac disease and inflammatory bowel disease. Headache. 2013;53(2):344-55 https://doi.org/10.1111/j.1526-4 610.2012.02260.x.

270. Gabrielli M, Cremonini F, Fiore G, Addolorato G, Padalino C, Candelli M, et al. Association between migraine and celiac disease: results from a preliminary case-control and therapeutic study. Am J Gastroenterol. 2003; 98(3):625-9 https://doi.org/10.1111/j.1572-0241.2003.07300.x.

271. Cicarelli G, Della Rocca G, Amboni M, Ciacci C, Mazzacca G, Filla A, et al. Clinical and neurological abnormalities in adult celiac disease. Neurol Sci. 2003;24(5):311-7 https://doi.org/10.1007/s10072-003-0181-4.

272. Lionetti E, Francavilla R, Maiuri L, Ruggieri M, Spina M, Pavone P, et al. Headache in pediatric patients with celiac disease and its prevalence as a diagnostic clue. J Pediatr Gastroenterol Nutr. 2009;49(2):202-7 https://doi. org/10.1097/MPG.0b013e31818f6389.

273. Ameghino L, Farez MF, Wilken M, Goicochea MT. Headache in Patients with Celiac Disease and Its Response to the Gluten-Free Diet. J Oral Facial Pain Headache. 2019;33(3):294-300 https://doi.org/10.11607/ofph.2079.

274. Zis P, Julian T, Hadjivassiliou M. Headache associated with coeliac disease: a systematic review and meta-analysis. Nutrients. 2018;10(10):1445 https://doi. org/10.3390/nu10101445.

275. Currie S, Hadjivassiliou M, Clark MJ, Sanders DS, Wilkinson ID, Griffiths PD, et al. Should we be 'nervous' about coeliac disease? Brain abnormalities in patients with coeliac disease referred for neurological opinion. J Neurol Neurosurg Psychiatry. 2012;83(12):1216-21 https://doi.org/10.1136/jnnp-2012-303281.

276. D'Amico D, Rigamonti A, Spina L, Bianchi-Marzoli S, Vecchi M, Bussone G. Migraine, celiac disease, and cerebral calcifications: a new case. Headache. 2005;45(9):1263-7 https://doi.org/10.1111/j.1526-4610.2005.00253_2.x.

277. Hadjivassiliou M, Grünewald RA, Lawden M, Davies-Jones GA, Powell T, Smith CM. Headache and CNS white matter abnormalities associated with gluten sensitivity. Neurology. 2001;56(3):385-8 https://doi.org/10.1212 WNL.56.3.385.

278. Balcı O, Yılmaz D, Sezer T, Hızlı Ş. Is Celiac Disease an Etiological Factor in Children With Migraine? J Child Neurol. 2016;31(7):929-31 https://doi.org/1 $0.1177 / 0883073816630088$.

279. Inaloo S, Dehghani SM, Farzadi F, Haghighat M, Imanieh MH. A comparative study of celiac disease in children with migraine headache and a normal control group. Turk J Gastroenterol. 2011;22(1):32-5 https://doi.org/10.4318/ tjg.2011.0153.

280. Alehan F, Ozçay F, Erol I, Canan O, Cemil T. Increased risk for coeliac disease in paediatric patients with migraine. Cephalalgia. 2008;28(9):945-9 https:// doi.org/10.1111/j.1468-2982.2008.01630.x.

281. Chehel Cheraghi S, Ebrahimi Daryani N, Ghabaee M. A survey on migraine prevalence in patients with inflammatory bowel disease - a single centre experience. Middle East J Dig Dis. 2016;8(4):282-8 https://doi.org/10.15171/ mejdd.2016.37.

282. Chang FY, Lu CL. Irritable bowel syndrome and migraine: bystanders or partners? J Neurogastroenterol Motil. 2013;19(3):301-11 https://doi.org/10. 5056/jnm.2013.19.3.301.

283. Liu Y, Xu F, Wheaton AG, Greenlund KJ, Thomas CW. The association between inflammatory bowel disease and migraine or severe headache among US adults: Findings from the National Health Interview Survey, 20152016. Headache. 2021 Apr;61(4):612-9. https://doi.org/10.1111/head.14087.

284. Cady RK, Farmer K, Dexter JK, Hall J. The bowel and migraine: update on celiac disease and irritable bowel syndrome. Curr Pain Headache Rep. 2012; 16(3):278-86 https://doi.org/10.1007/s11916-012-0258-y.

285. Goel G, Tye-Din JA, Qiao SW, Russell AK, Mayassi T, Ciszewski C, Sarna VK, Wang S, Goldstein KE, Dzuris JL, Williams $\sqcup$, Xavier RJ, Lundin KEA, Jabri B, Sollid LM, Anderson RP. Cytokine release and gastrointestinal symptoms after gluten challenge in celiac disease. Sci Adv. 2019;5(8):eaaw7756. https://doi.org/10.112 6/sciadv.aaw7756.

286. Bledsoe AC, King KS, Larson JJ, Snyder M, Absah I, Choung RS, et al. Micronutrient Deficiencies Are Common in Contemporary Celiac Disease
Despite Lack of Overt Malabsorption Symptoms. Mayo Clin Proc. 2019;94(7): 1253-60 https://doi.org/10.1016/j.mayocp.2018.11.036.

287. van Hemert S, Breedveld AC, Rovers JM, Vermeiden JP, Witteman BJ, Smits $M G$, et al. Migraine associated with gastrointestinal disorders: review of the literature and clinical implications. Front Neurol. 2014;21(5):241.

288. Hindiyeh N, Aurora SK. What the gut can teach us about migraine. Curr Pain Headache Rep. 2015;19(7):33 https://doi.org/10.1007/s11916-015-0501-4.

289. Arzani M, Jahromi SR, Ghorbani Z, Vahabizad F, Martelletti P, Ghaemi A, et al. School of Advanced Studies of the European Headache Federation (EHFSAS). Gut-brain Axis and migraine headache: a comprehensive review. J Headache Pain. 2020;21(1):15 https://doi.org/10.1186/s10194-020-1078-9.

290. Rahmoune H, Boutrid N. Migraine, Celiac Disease and Intestinal Microbiota. Pediatr Neurol Briefs. 2017;31(2):6 https://doi.org/10.15844/pedneurbriefs-31-2-3.

291. Mittal R, Debs LH, Patel AP, Nguyen D, Patel K, O'Connor G, et al. Neurotransmitters: the critical modulators regulating gut-brain axis. J Cell Physiol. 2017;232(9):2359-72 https://doi.org/10.1002/jcp.25518.

292. Villalón CM, VanDenBrink AM. The Role of 5-Hydroxytryptamine in the pathophysiology of migraine and its relevance to the design of novel treatments. Mini-Rev Med Chem. 2017;17(11):928-38 https://doi.org/10.21 74/1389557516666160728121050.

293. Mortimer MJ, Kay J, Gawkrodger DJ, Jaron A, Barker DC. The prevalence of headache and migraine in atopic children: an epidemiological study in general practice. Headache. 1993;33(8):427-31 https://doi.org/10.1111/j.152 6-4610.1993.hed3308427.x.

294. Wilkinson IA, Halliday JA, Henry RL, Hankin RG, Hensley MJ. Headache and asthma. J Paediatr Child Health. 1994;30(3):253-6 https://doi.org/10.1111/ j.1440-1754.1994.tb00628.x.

295. Davey G, Sedgwick P, Maier W, Visick G, Strachan DP, Anderson HR. Association between migraine and asthma: matched case-control study. $\mathrm{Br}$ J Gen Pract. 2002;52(482):723-7.

296. Ozge A, Ozge C, Oztürk C, Kaleagasi H, Ozcan M, Yalçinkaya DE, et al. The relationship between migraine and atopic disorders-the contribution of pulmonary function tests and immunological screening. Cephalalgia. 2006; 26(2):172-9 https://doi.org/10.1111/j.1468-2982.2005.01021.x.

297. Ku M, Silverman B, Prifti N, Ying W, Persaud Y, Schneider A. Prevalence of migraine headaches in patients with allergic rhinitis. Ann Allergy Asthma Immunol. 2006;97(2):226-30 https://doi.org/10.1016/S1081-1206(10)60018-X.

298. Aamodt AH, Stovner $\amalg$, Langhammer A, Hagen K, Zwart JA. Is headache related to asthma, hay fever, and chronic bronchitis? The Head-HUNT Study. Headache. 2007:47(2):204-12 https://doi.org/10.1111/j.1526-4610.2006.00597.x.

299. Tollefsen E, Langhammer A, Bjermer L, Romundstad P, Holmen TL. Allergy: a systemic disease? The HUNT and Young-HUNT study. Norway. Pediatr Allergy Immunol. 2008;19(8):730-6 https://doi.org/10.1111/j.1399-3038.2008.00732.x.

300. Gürkan F, Ece A, Haspolat K, Dikici B. Parental history of migraine and bronchial asthma in children. Allergol Immunopathol (Madr). 2000;28:15-7.

301. Lee YS, Lee GD, Lee JS, Rhee CK, Shim TS, Kim WS, et al. Is daily headache related to asthma? Results from a population-based survey. J Asthma. 2013; 50(7):745-50 https://doi.org/10.3109/02770903.2013.795587.

302. Martin VT, Fanning KM, Serrano D, Buse DC, Reed ML, Lipton RB. Asthma is a risk factor for new onset chronic migraine: results from the American migraine prevalence and prevention study. Headache. 2016;56(1):118-31 https://doi.org/10.1111/head.12731.

303. Gryglas A. Allergic rhinitis and chronic daily headaches: is there a link? Curr Neurol Neurosci Rep. 2016;16(4):33 https://doi.org/10.1007/s11910-016-0631-z.

304. Wang IC, Tsai JD, Lin CL, Shen TC, Li TC, Wei CC. Allergic rhinitis and associated risk of migraine among children: a nationwide population-based cohort study. Int Forum Allergy Rhinol. 2016;6(3):322-7 https://doi.org/10.1002/alr.21654.

305. Wei CC, Lin CL, Shen TC, Chen AC. Children with allergic diseases have an increased subsequent risk of migraine upon reaching school age. J Investig Med. 2018;66(7):1064-8 https://doi.org/10.1136/jim-2018-000715.

306. Martin VT, Taylor F, Gebhardt B, Tomaszewski M, Ellison JS, Martin GV, et al. Allergy and immunotherapy: are they related to migraine headache? Headache. 2011;51(1):8-20 https://doi.org/10.1111/j.1526-4610.2010.01792.x.

307. Aupiais C, Wanin S, Romanello S, Spiri D, Moretti R, Boizeau P, et al. Association between migraine and atopic diseases in childhood: a potential protective role of anti-allergic drugs. Headache. 2017;57(4):612-24 https:// doi.org/10.1111/head.13032.

308. Bektas H, Karabulut H, Doganay B, Acar B. Allergens might trigger migraine attacks. Acta Neurol Belg. 2017;117(1):91-5 https://doi.org/10.1007/s13760016-0645-y. 
309. Mansfield LE, Vaughan TR, Waller SF, Haverly RW, Ting S. Food allergy and adult migraine: double-blind and mediator confirmation of an allergic etiology. Ann Allergy. 1985;55(2):126-9.

310. Pradalier A, Weinman S, Launay JM, Baron JF, Dry J. Total IgE, specific lgE and prick-tests against foods in common migraine--a prospective study. Cephalalgia. 1983;3(4):231-4 https://doi.org/10.1046/j.1468-2982.1983.03 04231.x.

311. Finocchi C, Sivori G. Food as trigger and aggravating factor of migraine. Neurol Sci. 2012;33(Suppl 1):S77-80. https://doi.org/10.1007/s10072-012-1046-5.

312. Pascual J, Oterino A. IgG-mediated allergy: a new mechanism for migraine attacks? Cephalalgia. 2010;30(7):777-9 https://doi.org/10.1177/03331024103 64856.

313. Geiselman JF. The Clinical Use of IgG Food Sensitivity Testing with Migraine Headache Patients: a Literature Review. Curr Pain Headache Rep. 2019; 23(11):79. https://doi.org/10.1007/s11916-019-0819-4.

\section{Publisher's Note}

Springer Nature remains neutral with regard to jurisdictional claims in published maps and institutional affiliations.

Ready to submit your research? Choose BMC and benefit from:

- fast, convenient online submission

- thorough peer review by experienced researchers in your field

- rapid publication on acceptance

- support for research data, including large and complex data types

- gold Open Access which fosters wider collaboration and increased citations

- maximum visibility for your research: over $100 \mathrm{M}$ website views per year

At BMC, research is always in progress.

Learn more biomedcentral.com/submissions 